\title{
Inhibition mechanism of human sterol 0 -acyltransferase 1 by competitive inhibitor
}

7 University, Beijing Key Laboratory of Cardiometabolic Molecular Medicine, Beijing 100871,

$9{ }^{2}$ Key Laboratory of Bioorganic Chemistry and Molecular Engineering, Ministry of Education

10 and Beijing National Laboratory for Molecular Science, College of Chemistry and Molecular Engineering, Peking University, Beijing 100871, China,

$12{ }^{3}$ Department of Biochemistry and Cell Biology, Geisel School of Medicine at Dartmouth, 


\section{Abstract}

25 Sterol O-acyltransferase 1 (SOAT1) is an endoplasmic reticulum (ER) resident, multi-

26 transmembrane enzyme that belongs to the membrane-bound O-acyltransferase (MBOAT)

27 family ${ }^{1}$. It catalyzes the esterification of cholesterol to generate cholesteryl esters for cholesterol

28 storage $^{2}$. SOAT1 is a target to treat several human diseases ${ }^{3}$. However, its structure and

29 mechanism remain elusive since its discovery. Here, we report the structure of human SOAT1

30 (hSOAT1) determined by cryo-EM. hSOAT1 is a tetramer consisted of a dimer of dimer. The

31 structure of hSOAT1 dimer at $3.5 \AA$ resolution reveals that the small molecule inhibitor CI-976

32 binds inside the catalytic chamber and blocks the accessibility of the active site residues H460,

33 N421 and W420. Our results pave the way for future mechanistic study and rational drug design

34 of SOAT1 and other mammalian MBOAT family members. 


\section{Main}

48 Cholesterol is an essential lipid molecule in the cell membranes of all vertebrate. It is important

49 for maintaining the fluidity and integrity of the membrane and is the precursor for the

50 biosynthesis of other crucial endogenous molecules, such as steroid hormones and bile acids. In

51 addition, cholesterol can modulate the activity of many membrane proteins such as GPCR ${ }^{4}$ and

52 ion channels ${ }^{5}$. The concentration of cellular free cholesterol is highly regulated ${ }^{2}$. Excessive

53 intracellular cholesterol may form cholesteryl esters, which are catalyzed by the enzyme, sterol

54 O-acyltransferase (SOAT), also called acyl-coenzyme A: cholesterol acyltransferase (ACAT).

55 SOAT catalyzes the reaction between long chain fatty acyl-CoA and intracellular cholesterol to

56 form the more hydrophobic cholesteryl ester, which is then stored in lipid droplets within the cell

57 or transported in secreted lipoprotein particles to other tissues that need cholesterol. In addition

58 to cholesterol, SOAT can use multiple sterols as substrates and activators ${ }^{3}$. Because of its

59 functional importance, SOAT1 is a potential drug target for Alzheimer's disease ${ }^{6}$,

60 atherosclerosis ${ }^{7}$ and several types of cancers ${ }^{8-11}$.

61 Previous studies have shown that SOAT1 is an ER-localized multi-transmembrane protein that is

62 evolutionary conserved from yeast to humans ${ }^{12}$. There are two SOAT enzymes in mammals:

63 SOAT1 and SOAT2, which have a protein sequence identity of 48\% in human (258 out of 537

64 residues aligned). SOAT1 is ubiquitously expressed in many types of cells ${ }^{13}$; while SOAT2 is

65 mainly expressed in the small intestine and liver ${ }^{14}$. Due to the pathophysiological importane of

66 SOAT, many SOAT inhibitors of various strutural types have been made. Among them, the

67 small molecule SOAT inhibitor CI-976 exhibit competitive inhibition against fatty acyl-CoA ${ }^{15}$.

68 SOAT is the founding member of the membrane-bound O-acyltransferase (MBOAT) enzyme

69 family, which transfers the acyl chain onto various substrates, including lipids, peptides and 
70 small proteins. There are 11 MBOAT family members in humans ${ }^{1}$, which participate in many

71 physiological processes, such as the last step of triglyceride biosynthesis catalyzed by acyl-CoA:

72 diacylglycerol acyltransferase 1 (DGAT1), the maturation of hedgehog morphogen catalyzed by

73 hedgehog acyltransferase (HHAT), and the acylation of peptide hormone ghrelin catalyzed by

74 ghrelin O-acyltransferase (GOAT). Recently, the X-ray crystal structure of DltB from

75 Streptococcus thermophilus was determined and is the only available structure of an MBOAT

76 family member ${ }^{16}$. The low-sequence conservation between DltB and SOAT (14.6\% identity)

77 hindered the accurate modeling of the human SOAT1 structure. Therefore, despite the important

78 physiological functions of human SOAT enzymes, their architecture and mechanism remain

79 elusive due to a lack of high-resolution structures. In this study, several human SOAT1

80 (hSAOT1) structures were determined. These structures reveal the architecture of hSOAT1, the

81 binding sites of the competitive inhibitor CI-976, and provide a structural basis to understand the

82 molecular mechanism of these enzymes.

\section{Structure determination}

86 N-terminal GFP-tagged full-length (1-550) and N-terminal truncated hSOAT1 (66-550),

87 solubilized in detergent micelles migrated before and after mouse TPC1 channel, which is a

88 well-characterized dimeric channel with a molecular weight of $189 \mathrm{kDa}^{17}$ (Fig. S1a, S1b). This

89 is consistent with previous studies, showing that hSOAT1 is a tetramer with a molecular weight

90 of around $260 \mathrm{kDa}^{18}$ and that hSOAT1 became predominantly dimeric with the deletion of the

$91 \quad \mathrm{~N}$-terminal tetramerization domain ${ }^{19}$. In order to measure the acyltransferase activity of purified

92 protein, we developed the in vitro hSOAT1 assay using fluorescence-labeled NBD-cholesterol 
93 and oleoyl-CoA as substrates based on the previously reported SOAT1 whole cell assay ${ }^{20}$ (Fig.

94 1a and Fig. S1c-h). The results show that the activity of hSOAT1 tetramer is linear within the

95 first $15 \mathrm{~min}$ (Fig. S1h), and both the purified tetramer and dimer hSOAT1 protein exhibited

96 cholesterol-activated O-acyltransferase activity in detergent micelles (Fig. 1b, Fig. S1d-h).

97 Moreover, the SOAT enzyme activity is inhibited by CI-976 in a dose-dependent manner (Fig.

98 1c).

99 To investigate the structure of hSOAT1, we prepared the sample of hSOAT1 in the presence of

100 CI-976 in detergent micelles for cryo-EM analysis. The 3D classification showed the hSOAT1

101 protein exhibited severe conformational heterogeneity (Fig. S2). One of the 3D classes can be

102 further refined to $12 \AA$ and the map allowed the visualization of the general shape of hSOAT1, in

103 which the cytosolic $\mathrm{N}$ terminal oligomerization domain lays above the transmembrane domain.

104 Moreover, the central slice of the transmembrane domain density map indicated the hSOAT1 is a

105 tetramer composed of dimer of dimers (Fig. S2d), which is consistent with previous biochemical

106 data ${ }^{19}$. To further stabilize the transmembrane domain, we reconstituted hSOAT1 into a lipid

107 nanodisc (Fig. S3a, S3b) for cryo-EM analysis (Fig. S4). The top view of 2D class averages of

108 the nanodisc sample had markedly enhanced features and confirmed the transmembrane region

109 of hSOAT1 to be a dimer of dimers (Fig. S4b). However, some 2D class averages in top views

110 showed that one distinct dimer was adjacent to another blurry but still distinguishable dimer (Fig.

111 S4b), suggesting the dimer-dimer interface is mobile. Through multiple rounds of 2D and 3D

112 classification, two 3D classes with discernable transmembrane helix densities were isolated.

113 Subsequent refinements generated reconstructions at resolutions of $8.2 \AA$ (for the oval-shaped

114 tetramer) and $7.6 \AA$ (for the rhombic-shaped tetramer) (Fig. S4c, S4d). The oval-shaped structure

115 occupies a 3D space of $170 \AA \times 120 \AA \times 50 \AA$ and the shape is similar to 3D Class 1 observed in 
116 detergent micelles (Fig. S2), and the rhombic-shaped structure occupies $185 \AA \times 110 \AA \times 50 \AA$

117 (Fig. 2), similar to the 3D Class 2 observed in detergent micelles (Fig. S2). The N terminal

118 tetramerization domain is invisible in both maps probably due to its flexibility. These two

119 structures reveal that the dimer-dimer interfaces of oval-shaped and rhombic-shaped hSOAT1

120 are distinct (Fig. 2b, d), correlating with the 3D heterogeneity observed in detergent micelles.

121 This suggests the interfaces between dimers are unstable and dynamic in nature, which in turn

122 hampered high-resolution structure determination. To overcome the conformational

123 heterogeneity in the tetrameric hSOAT1 sample, the functional dimer construct (hSOAT1 66-

124 550) was expressed and purified. The protein was reconstituted into the nanodisc in the presence

125 of inhibitor CI-976 (Fig. S3c, S3d). Subsequent 3D reconstruction generated a $3.5 \AA$ cryo-EM

126 map, which allowed the model to be built de novo (Fig. 3a, Fig. S5-6, and Table S1).

128 Structure of hSOAT1 dimer

129 The hSOAT1 dimer has a symmetric "rubber raft" shape and occupies a $135 \AA$ × $70 \AA \times 50 \AA$

130 three-dimensional space (Fig. 3a). Each hSOAT1 subunit is composed of nine transmembrane

131 helices (Fig. 3b), which is consistent with previous prediction based on the biochemical data ${ }^{21}$.

132 The first 52 amino acids (66-117) of the dimeric hSOAT1 were invisible in the cryo-EM map,

133 presumably due to their high flexibility (Fig. 3c, d). Notably, this region has the low sequence

134 conservation between SOATs from different species and paralogues. The cytosolic pre- $\alpha$ A loop

135 runs parallel to the membrane. The amphipathic $\alpha$ A floats on the putative lipid bilayer with

136 hydrophobic di-leucine motifs facing the membrane and connects to M1 via a near $90^{\circ}$ turn (Fig.

137 3d). M1 is linked to the long tilted M2-M4 tri-helix bundle by an ER-luminal loop and a short

138 helix $\alpha \mathrm{B}$ (Fig. 3d). The six transmembrane helices M4-9 form a funnel-shaped central cavity, 
139 which is capped by the cytosolic helices $\alpha \mathrm{C}, \alpha \mathrm{D}$, and $\alpha \mathrm{E}$ on the top. At the end of M9, a C-

140 terminal ER luminal loop (CT loop) is cross-linked by the disulfide bond formed between C528

141 and C546 (Fig. 3d). It was previously reported that this loop is important for hSOAT activity and

142 stability ${ }^{22,23}$. Indeed, the CT loop interacts with both the luminal M7-M8 loop and the M5-M6

143 loop (Fig. 3d) at the ER luminal side. Based on the sequence homology (Fig. S7), the closely

144 related SOAT2 and the distal related DGAT1 enzymes might have a similar transmembrane

145 domain topology to hSOAT1 reported here. In addition, the TM2-9 of hSOAT1 share a similar

146 structural fold with H4-H16 of DltB ${ }^{16}$, with core RMSD of $3.2 \AA$ for 227 structurally aligned

147 residues, despite of their low sequence identity (Fig. 3e), suggesting a common evolutionary

148 origin of the MBOAT family enzymes.

150 Dimer interface

151 In contrast to the monomeric DltB protein, the functional unit of hSOAT1 is a tightly packed

152 dimer, with a dimer interface area of $6,520 \AA^{2}$. The two hSOAT1 protomers interact through the

153 M1, M6, M6- $\alpha$ D loop and M9 helices in a symmetric way (Fig. 4a and b). In the inner leaflet of

154 the ER membrane, M144, A147, L148 and L151 on M1 of one subunit interact with I370 and

155 F378 on M6, and V501, W504 and F508 of M9 of the other subunit (Fig. 4c and d). In the outer

156 leaflet of ER membrane, V158 and V159 on M1 interact with V363 on M6 of the other subunit

157 (Fig. 4c and d). The residues that form the dimer interface are mostly hydrophobic and interact

158 with each other in a shape-complementary manner. 
161 Previous studies suggest that the conserved H460 on M7 is crucial for hSOAT1 activity and is

162 the putative catalytic residue ${ }^{21}$. The side chain of $\mathrm{H} 460$ points towards the interior of the central

163 cavity cradled by M4-M9 (Fig. 5a and b). These structural observations suggest this central

164 cavity is the chamber where the acyl transfer reaction takes place. In accordance with this,

165 previous studies have also identified several residues in the central cavity that are important for

166 hSOAT1 function. Mutations of residues on M7 and M8 affect the catalytic activity ${ }^{24,25}$. C467 at

167 the end of M7 is the major target site for p-chloromercuribenzene sulfonic acid-mediated SOAT1

168 inactivation ${ }^{26}$. These data also indicate that the local environment in the central cavity is

169 important for the catalytic reaction.

170 The reaction chamber is covered by a lid formed by M4- $\alpha \mathrm{C}$ loop, $\alpha \mathrm{C}, \mathrm{M} 6-\alpha \mathrm{D}$ loop, $\alpha \mathrm{D}$ and $\alpha \mathrm{E}$

171 on the cytosolic side. It is suggested that part of the cytosolic lid, residues 403-409 on M6- $\alpha \mathrm{D}$

172 loop, may be involved in the binding of fatty acyl-CoA ${ }^{27}$. To further explore the role of the

173 residues in this region, we performed alanine or cysteine mutagenesis of conserved residues

174 within region amino acids 406-422 (from M6- $\alpha \mathrm{D}$ loop to $\alpha \mathrm{D}$, Fig. 5c), and analyzed the effects

175 of mutations after transient expressions of each of these mutant plasmid DNAs in a CHO cell

176 clone AC29, that is devoid of endogenous SOAT activity, but regains enzyme activity upon

177 transient expression of hSOAT plasmid DNA ${ }^{28}$. The results showed that mutating any of the

178 following residues W407, S414, Y416, Y417, R418, W420, and N421 to alanines or cysteines

179 caused loss in normalized hSOAT1 enzyme activity (by greater than 90\%) without severely

180 lowering the cellular hSOAT1 protein expression in transfected cells (Fig. 5d). Because the

181 hydrophilic side chains of S414 and R418 on $\alpha \mathrm{D}$ face the cytosolic side of SOAT1, S414 and

182 R418 might be involved in functions important for hSOAT1 activity, such as binding of highly 
183 hydrophilic CoA group of fatty acyl-CoA substrate. These results further emphasize the

184 important role of the cytosolic lid of the reaction chamber in the enzymatic reaction.

186 Inhibitor and ligands binding sites

187 A strong extra non-protein density was found in the central cavity and the size and shape of the 188 density matched that of the inhibitor CI-976, which was included during cryo-EM sample 189 preparation (Fig. S8a). By comparing the current map with the maps without CI-976 (as 190 described later), we proposed that this "nonprotein material" represents the CI-976 molecule.

191 The large trimethoxyphenyl group of CI-976 is sandwiched between the catalytic residue H460 192 on M7, and residues N421 as well as W420 on the $\alpha \mathrm{D}-\alpha \mathrm{E}$ loop (Fig. 5a, b), all of which are 193 crucial for the catalytic activity of hSOAT1. The elongated dodecanamide tail of CI-976 extends 194 in the cavity and interacts with M6 and M9. The binding position of CI-976, right in the catalytic 195 center, suggests that it inhibits the enzyme by precluding substrate loading into the catalytic 196 center, which is consistent with the competitive behavior of CI-976 ${ }^{15}$. Moreover, it has been 197 reported that certain residues on M9 are responsible for the selectivity of subtype-specific SOAT 198 inhibitors, such as pyripyropene $\mathrm{A}^{29}$. This further suggests that the catalytic chamber might be a 199 common binding site for inhibitors with diverse chemical structures.

200 There are several extra non-protein densities observed in the cryo-EM map. One density (density 201 A) is close to the dimer interface. It is surrounded by L129, L132 and L133 on the hydrophobic 202 side of $\alpha$ A, F145 on M1, C333 on M5, F382 on M6 and W408 on M6- $\alpha$ D loop (Fig. S8c). The 203 shape of this density is close to cholesterol, suggesting this ligand might be a tightly-bound 204 sterol-like molecule that was carried on during membrane protein extraction and purification. 205 SOATs are allosteric enzymes that can be activated by cholesterol ${ }^{3}$ and it is predicted that 
SOATs have two functional distinct cholesterol binding sites. One site is the substrate binding

207 site and the other is the allosteric activating site that provides the feedback regulation mechanism

208 regarding cholesterol concentration in the ER ${ }^{3}$. On the other hand, previous work showed that

209 SOAT1 exhibits only low affinity binding towards cholesterol, either as substrate or as activator,

210 with dissociation constant at sub-millimolar concentration ${ }^{30}$. Therefore, we speculate that the

211 molecule in density A is neither a cholesterol substrate nor a cholesterol activator, but a sterol-

212 like molecule bound to the enzyme in the sample preparation procedure. Another elongated

213 density (density B) is inside the central cavity and surrounded by F258 and R262 on M4, F384

214 and W388 on M6, P304 on $\alpha$ C-M5 linker and V424 on $\alpha \mathrm{E}$ (Fig. S8e). One additional density

215 (density C) is on the ER luminal side of the central cavity and surrounded by Y176 on $\alpha \mathrm{B}$, S519,

216 W522 and Y523 on M9, L468 on M7-M8 linker, P250 on M3-M4 linker (Fig. S8g). The exact

217 identities of these densities A-C and their roles on the hSOAT1 function remain elusive.

218 In order to gain more mechanistic insights into the catalytic mechanism of hSOAT1 and to trap

219 the catalytic reaction in a transition state, we designed and synthesized a compound that might

220 mimic the catalytic transition intermediate. Inspired by the previous work on GOAT ${ }^{31}$, we

221 hypothesized that the catalytic reaction intermediate of hSOAT1 might be a ternary complex of

222 sterol, acyl-CoA and the enzyme. Therefore, the covalent linkage of sterol and acyl-CoA would

223 yield a competitive inhibitor with a higher affinity than each individual substrate alone.

224 Pregnenolone was previously reported to be a substrate of hSOAT1 with a lower $\mathrm{K}_{\mathrm{m}}$ and better 225 solubility than cholesterol ${ }^{32}$. In the current study, CoA group was chemically covalently linked 226 with stearoyl- pregnenolone to generate a bi-substrate analogue for hSOAT1 (BiSAS) (Fig. S9a).

227 Indeed, BiSAS inhibited the purified hSOAT1 enzyme in the in vitro NBD-cholesterol based 228 assay (Fig. S9b). A cryo-EM sample of hSOAT1 dimer was prepared in the presence of BiSAS 
23011 and Table S1). This map was compared with the CI-976 bound map and was found to be

231 similar overall, with a real space correlation of 0.9 . We anticipated that BiSAS might mimic both

232 substrates of hSOAT1 and might occupy the substrate-binding pocket while cholesterol might

233 only bind at the activating site. In contrast to our prediction, in the BiSAS map, the strong

234 continuous density of CI-976 found in the central cavity of the CI-976 bound map was replaced

235 by weak residual densities that were not continuous (Fig. S8b), indicating the absence of full-

236 sized BiSAS molecule, probably due to the low affinity or incompatibility of BiSAS in the

237 nanodisc sample preparation conditions. Retrospectively, the large size of BiSAS molecule

238 would not fit into the hSOAT1 structure in the current conformation. In addition, we did not

239 observe any extra density that would suggest the presence of activating cholesterol either,

240 probably due to the low affinity of activating cholesterol on hSOAT1 ${ }^{30}$. Instead, most likely, the

241 BiSAS map represents the apo resting state of hSOAT1. Interestingly, all three additional non-

242 protein ligand densities (density A-C) present in the CI-976 map were also observed in the

243 BiSAS map (Fig. S8d, S8f, S8h), further suggesting their tight associations with the hSOAT1

244 protein and likely their functional importance as well.

246 A working model for hSOAT1 activation

247 SOAT catalyzes the esterification reaction between acyl-CoA and cholesterol. The surface

248 representation of the hSOAT1 monomer shows an intra-membrane tunnel from outside of the

249 molecule into the reaction chamber. The tunnel is located between M4 and M5, and is mainly

250 hydrophobic. This lateral tunnel within the transmembrane domain of hSOAT1 might be the 251 substrate or product transfer pathway for hydrophobic molecules. The other substrate, fatty acyl- 
252 CoA, is amphipathic with a hydrophobic tail and a highly hydrophilic CoA group. The cytosolic

253 acyl-CoA can access the central reaction chamber only from the cytosolic side of hSOAT1.

254 However, the surface representation of the hSOAT1 dimer shows that the reaction chamber is

255 completely shielded from the cytosolic side by the two short $\alpha \mathrm{D}-\alpha \mathrm{E}$ helices and associated

256 intracellular loops (Fig. 5e-g). This suggests that the current structure represents a resting state

257 with relatively low catalytic activity, in which the putative catalytic residue $\mathrm{H} 460$ is less

258 accessible to the acyl-CoA substrate (Fig. S11). Therefore an activation step that opens the

259 reaction chamber, probably caused by sterol binding at the allosteric activator site, is required for

260 the sterol-dependent fully activation of hSOAT1 ${ }^{4}$.

261 The structures of human SOAT1 presented here provide the a high-resolution view of the

262 architecture and domain organization of this important enzyme and shed light on the structure of

263 other closely related MBOAT family proteins, such as SOAT2 and DGAT1. This work not only

264 paves the way towards a better mechanistic understanding of SOAT1-catalyzed reaction, but also

265 provides a template for structure-based inhibitor design to target several human diseases.

\section{Acknowledgement}

268 The cDNAs of human SOAT1 and SOAT2 were kindly provided by Jiahuai Han. Cryo-EM data

269 collection was supported by Electron microscopy laboratory and Cryo-EM platform of Peking

270 University with the assistance of Xuemei Li, Daqi Yu, Xia Pei, Bo Shao, Guopeng Wang, and

271 Zhenxi Guo. Part of structural computation was also performed on the Computing Platform of

272 the Center for Life Science and High-performance Computing Platform of Peking University.

273 This work is supported by grants from the Ministry of Science and Technology of China

274 (National Key R\&D Program of China, 2016YFA0502004 to L.C.), National Natural Science 
275 Foundation of China (91957201, 31622021, 31870833 and 31821091 to L.C., 31521004,

27621672011 and 21822101 to T. L.), Beijing Natural Science Foundation (5192009 to L.C.), and

277 Young Thousand Talents Program of China to L.C, NIH grants in U.S.A. (R01AG037609 and

278 AG063544 to T.Y. Chang and C.C.Y. Chang). C.G. is supported by a Boehringer-Ingelheim

279 postdoctoral fellowship.

280

281 Author Contribution

282 Lei Chen initiated the project. Chengcheng Guan developed the fluorescence-based activity

283 assay. Chengcheng Guan purified proteins and prepared the cryo-EM samples with the help of

284 Yange Niu. Chengcheng Guan collected the cryo-EM data with the help of Jing-Xiang Wu and

285 Yunlu Kang. Chengcheng Guan processed the cryo-EM data with the help of Lei Chen. Lei Chen

286 built and refined the atomic model. Si-Cong Chen synthesized the BiSAS inhibitor under the

287 guidance of Tuoping Luo. Koji Nishi, Catherine C. Y. Chang and Ta-Yuan Chang did the 288 enzymatic activity assays based on radioactive substrates. All authors contributed to the 289 manuscript preparation.

290 Competing interests

291 The authors declare no competing interests.

292 Materials \& Correspondence

293 Correspondence to Lei Chen. Any materials that are not commercially available can be obtained

294 upon reasonable request.

\section{Data availability}

296 The cryo-EM map of hSOAT1 tetramer in oval shape, hSOAT1 tetramer in rhombic shape, 297 hSOAT1 dimer bound with CI-976 and in apo resting state have been deposited in the EMDB 
under ID codes EMD-0829, EMD-0830, EMD-0831 and EMD-0832. The atomic coordinates of hSOAT1 dimer bound with CI-976 and in apo resting state have been deposited in the PDB under ID codes 6L47 and 6L48.

\section{Methods}

\section{Cell culture}

304 Sf9 insect cells were cultured in Sf-900 III serum-free medium (SFM; Thermo Fisher Scientific)

305 or in SIM SF (Sino Biological) at $27{ }^{\circ} \mathrm{C}$. HEK293F cells were cultured at $37{ }^{\circ} \mathrm{C}$ with $6 \% \mathrm{CO} 2$ 306 and 70\% humidity in Free Style 293 medium (Thermo Fisher Scientific) supplemented with 1\% 307 fetal bovine serum (FBS).

\section{Chemical synthesis of BiSAS}

309 To the solution of $\alpha$-bromo stearic acid (727 mg, $2 \mathrm{mmol}, 1.0$ equiv), pregnenolone (632 $\mathrm{mg}, 2$

310 mmol, 1.0 equiv) and dicyclohexylcarbodiimide (DCC, $495 \mathrm{mg}, 2.4 \mathrm{mmol}, 1.2$ equiv) in 311 dichloromethane (DCM, $30 \mathrm{~mL}$ ) was added 4-dimethylaminopyridine (DMAP, $293 \mathrm{mg}, 2.4$

312 mmol, 1.2 equiv). The solution was stirred at room temperature for $24 \mathrm{~h}$. The crude product was 313 purified by column chromatography (Hexanes: Ethyl acetate $=10: 1$ ) to obtain the $\alpha$-bromo ester 314 (747 mg, $57 \%$ yield) as a white solid. ${ }^{1} \mathrm{H} \mathrm{NMR}\left(400 \mathrm{MHz}, \mathrm{CDCl}_{3}\right) \delta 5.39(\mathrm{~d}, \mathrm{~J}=5.1 \mathrm{~Hz}, 1 \mathrm{H})$, $3154.67(\mathrm{qd}, \mathrm{J}=11.3,9.5,4.2 \mathrm{~Hz}, 1 \mathrm{H}), 4.17(\mathrm{t}, \mathrm{J}=7.4 \mathrm{~Hz}, 1 \mathrm{H}), 2.54(\mathrm{t}, \mathrm{J}=8.9 \mathrm{~Hz}, 1 \mathrm{H}), 2.40-2.32$ $316(\mathrm{~m}, 2 \mathrm{H}), 2.12(\mathrm{~s}, 4 \mathrm{H}), 2.08-1.84(\mathrm{~m}, 6 \mathrm{H}), 1.75-1.58(\mathrm{~m}, 4 \mathrm{H}), 1.56-1.39(\mathrm{~m}, \mathrm{H}), 1.37-1.11$ $317(\mathrm{~m}, 32 \mathrm{H}), 1.03(\mathrm{~s}, 3 \mathrm{H}), 0.88(\mathrm{t}, \mathrm{J}=6.7 \mathrm{~Hz}, 3 \mathrm{H}), 0.63(\mathrm{~s}, 3 \mathrm{H}) .{ }^{13} \mathrm{C} \mathrm{NMR}\left(101 \mathrm{MHz}, \mathrm{CDCl}_{3}\right) \delta$ $318209.69,169.49,139.39,122.83,77.48,77.16,76.84,75.51,63.81,56.96,49.99,46.72,44.12$, $31938.92,37.69,37.04,36.74,35.04,32.08,31.94,31.91,31.71,29.84,29.83,29.81,29.73,29.61$, 
322 To the solution of $\alpha$-bromo ester obtained above (27 mg, $40 \mu \mathrm{mol}, 1.0$ equiv.) and CoA-SH (62 $323 \mathrm{mg}, 80 \mu \mathrm{mol}, 2.0$ equiv) in $N, N$-dimethyllformamide (DMF, $1 \mathrm{~mL}$ ) was added triethylamine

324 (TEA, $56 \mu \mathrm{L}, 0.4 \mathrm{mmol}, 10$ equiv). The solution was stirred under nitrogen atmosphere at $35^{\circ} \mathrm{C}$ 325 overnight. The crude product was purified by reverse phase HPLC (Water : Acetonitrile $=50$ : 32650 to $5: 95)$ to obtain BiSAS in bis(triethylammonium) salt form $(23.8 \mathrm{mg})$ as a colorless solid.

$327{ }^{1} \mathrm{H}$ NMR $\left(500 \mathrm{MHz}, \mathrm{D}_{2} \mathrm{O}\right) \delta 8.44(\mathrm{~s}, 1 \mathrm{H}), 8.06(\mathrm{~s}, 1 \mathrm{H}), 6.04(\mathrm{~s}, 1 \mathrm{H}), 5.27(\mathrm{~s}, 1 \mathrm{H}), 4.89-3.72(\mathrm{~m}$, $3289 \mathrm{H}), 3.65-3.20(\mathrm{~m}, 6 \mathrm{H}), 3.10(\mathrm{q}, \mathrm{J}=7.2 \mathrm{~Hz}, 8 \mathrm{H}), 2.89-1.73(\mathrm{~m}, 19 \mathrm{H}), 1.42-1.00(\mathrm{~m}, 48 \mathrm{H})$, $3290.88(\mathrm{~s}, 3 \mathrm{H}), 0.77(\mathrm{~s}, 6 \mathrm{H}), 0.72-0.60(\mathrm{~m}, 3 \mathrm{H}), 0.50(\mathrm{~s}, 3 \mathrm{H}) . \mathrm{HRMS}(\mathrm{ESI}): \mathrm{m} / \mathrm{z}$ calcd for $330 \mathrm{C}_{60} \mathrm{H}_{99} \mathrm{~N}_{7} \mathrm{O}_{19} \mathrm{P}_{3} \mathrm{~S}^{-}[\mathrm{M}-\mathrm{H}]^{-}:$1346.593480, found 1346.591330.

\section{Constructs}

332 We cloned human SOAT1 (Hs_SOAT1), human SOAT2 (Hs_SOAT2), Xenopus laevis SOAT1 333 (X1_SAOT1), chicken SOAT1 (Gg_SAOT1) and zebrafish SOAT1 (Dr_SOAT1) into NGFP 334 tagged BacMaM vector for screening by FSEC methods ${ }^{33}$. The screening procedures identified 335 human SOAT1 as a putative target with reasonable expression level and elution profile. cDNAs 336 of human SOAT1 full-length (1-550), SOAT1-dimer (66-550) were cloned into a modified 337 BacMaM vector, with N-terminal His ${ }_{7}$-strep-GFP tags ${ }^{34}$.

\section{Protein expression and purification}

339 The BacMam expression system was used for large-scale expression of human SOAT1. The 340 BacMaM viruses were added into suspended HEK293F cells (grown in FreeStyle 293 medium + $\left.3411 \% \mathrm{FBS}, 37^{\circ} \mathrm{C}\right)$. Sodium butyrate $(10 \mathrm{mM})$ was added to the culture 12 hours post-infection to 342 promote protein expression and the temperature was lowered to $30^{\circ} \mathrm{C}$. Cells were harvested 60 
343 hours post-infection and washed with TBS buffer $\left(20 \mathrm{mM}\right.$ Tris $\mathrm{pH} 8.0$ at $\left.4^{\circ} \mathrm{C}, 150 \mathrm{mM} \mathrm{NaCl}\right)$.

344 Cell pellets were frozen at $-80^{\circ} \mathrm{C}$ for later use.

345 The cell pellets were resuspended in TBS buffer supplemented with protease inhibitors $(2 \mu \mathrm{g} / \mathrm{ml}$

346 leupepetin, $2 \mu \mathrm{g} / \mathrm{ml}$ pepstatin, $2 \mu \mathrm{g} / \mathrm{ml}$ aprotonin and $1 \mathrm{mM}$ PMSF). Unless stated otherwise, all

347 buffers used for purification were supplemented with inhibitor either $1 \mu \mathrm{M}$ inhibitors CI-976 or

348 BiSAS. The cells were broken by sonication and centrifuged at 8,000 rpm for 10 min with

349 JA25.5 rotor (Beckman) to remove cell debris. The supernatant was centrifuged at 40,000 rpm

350 for $1 \mathrm{~h}$ in Ti45 rotor (Beckman) to harvest cell membrane in pellets. The membrane pellets were

351 homogenized in TBS, solubilized by $1 \%$ digitonin for $2 \mathrm{~h}$ at $4^{\circ} \mathrm{C}$, and centrifuged at $40,000 \mathrm{rpm}$

352 for $1 \mathrm{~h}$. The supernatant was loaded onto a $1 \mathrm{ml}$ prepacked strep-tactin superflow high-capacity

353 column (IBA) and washed using TBS buffer with $0.1 \%$ digitonin. The binding protein was eluted

354 using TBS buffer with $0.1 \%$ digitonin and $10 \mathrm{mM}$ desthiobiotin. The eluted proteins were

355 digested with PreScission protease to remove tags and further purified by superose-6 increase

356 column (GE Healthcare) in TBS buffer with $0.1 \%$ digitonin or $40 \mu \mathrm{M}$ GDN. Buffers were not

357 supplemented with inhibitors during the purification of proteins used for the activity assay.

358 Purified protein were either directly used for experiments or flash frozen in liquid nitrogen for

359 storage at $-80^{\circ} \mathrm{C}$. Stored protein was thawed on ice and centrifuged to remove precipitates before

360 further experiments.

\section{SOAT1 activity assays using ${ }^{3} \mathbf{H}-0 l e a t e$ in intact cells}

362 This assay was designed to measure the rate of ${ }^{3} \mathrm{H}$-cholesteryl oleate biosynthesis in intact

363 cells. Mutant CHO AC29 cells that lack endogenous SOAT activity were cultured in 6-well

364 plates at $37^{\circ} \mathrm{C}$ and transiently transfected with DNAs from various single amino acid

365 substitutions of hSOAT1 as indicated. Unless stated otherwise, each construct contained the $6 \mathrm{x}$ 
His tag at the N-terminus. We used hSOAT1 that contained the C92A substitution as the "wild type" hSOAT1. Control experiments showed that the SOAT activity of the C92A mutant remained the same as the wild type ${ }^{21}$ but the C92A substitution greatly diminished the SOAT1 protein aggregation that occurred in vitro during the SDS-PAGE process.

371 trypsinization. One part was used to monitor the hSOAT protein expression by Western blot

372 analysis, using the SOAT1 specific antibodies DM10 as the probe, as described ${ }^{12}$, with the

373 intensity of the WT hSOAT protein set as 1.0. The other two parts of the transfected cells were

374 used to monitor the SOAT enzyme activity, by incubating the intact cells to $20 \mu \mathrm{l}$ of ${ }^{3} \mathrm{H}-$

375 oleate/fatty acid free BSA $\left(7.5 \times 10^{6} \mathrm{dpm} / \mu \mathrm{l}\right)$ for $20 \mathrm{~min}$. The amount of ${ }^{3} \mathrm{H}$-cholesteryl oleate

376 produced was determined by the procedure previously described ${ }^{22,29}$. Briefly, after ${ }^{3} \mathrm{H}-$

377 oleate/BSA pulse, cells were rinsed with PBS, harvested in $1 \mathrm{~mL}$ per well of $0.1 \mathrm{M} \mathrm{NaOH}$,

378 incubated at RT for $30 \mathrm{~min}$. The cell homogenates were transferred to13x $100 \mathrm{~mm}$ size glass

379 tubes; then neutralized by adding $67 \mu \mathrm{l}$ of $3 \mathrm{M} \mathrm{HCl}$, and buffered with $50 \mu \mathrm{l}$ of $1 \mathrm{M} \mathrm{K}_{2} \mathrm{HPO}_{4} .80$

$380 \mu \mathrm{g}$ per tube of non-radiolabeled cholesteryl oleate was added as carrier for identification

381 purposes. Cellular lipids in each tube were extracted with $3 \mathrm{~mL}$ of $\mathrm{CHCl}_{3}: \mathrm{MeOH}$ at 2:1

382 followed by adding $1 \mathrm{~mL}$ of $\mathrm{H}_{2} \mathrm{O}$. The bottom chloroform phase that contained the lipid

383 samples were dried under $\mathrm{N}_{2}$, then redissolved in $80 \mu 1$ of ethyl acetate and spotted onto TLC

384 plates (Anatech), with petroleum ether:ether:acetic acid (90:10:1) as the solvent system. After

385 TLC, the plates were air-dried, the cholesteryl oleate bands (at Rf 0.9) were identified by briefly

386 staining the TLC plates with iodine vapor. The cholesteryl oleate bands were scraped into

387 scintillation vials and counted in a scintillation counter after addition of $3 \mathrm{~mL}$ per vial of

388 Ecoscint O. The enzyme activity of each mutant hSOAT1 was estimated relative to that of WT 
hSOAT1, with the protein content of each mutant hSOAT1 normalized with that of the WT hSOAT.

\section{SOAT1 activity assay using NBD-cholesterol}

392 The mixed micelles with $2.8 \mathrm{mM}$ cholesterol/11.2 $\mathrm{mM}$ PC/18.6 mM taurocholate were prepared

393 as described previously ${ }^{35}$. The tetrameric or dimeric hSOAT1 enzyme was prepared in GDN

394 detergent. First, $10 \mu \mathrm{l} 2 \mathrm{M} \mathrm{KCl}, 5 \mu \mathrm{l} \% \mathrm{BSA}, 1 \mu \mathrm{l}$ SOAT1 protein $\left(\mathrm{A}_{280}=0.5\right), 5 \mu 1$ micelles, $40 \mu \mathrm{l}$

395 TBS buffer with $40 \mu \mathrm{M}$ GDN were mixed with TBS with $0.5 \%$ CHAPS to reach the volume of

$396100 \mu \mathrm{l}$ and incubated at $37^{\circ} \mathrm{C}$ for $2 \mathrm{~min}$. In order to measure the $\mathrm{IC}_{50}$ of inhibitors, different

397 concentrations of given inhibitors were added, as indicated. Then, $1.25 \mu 10.2 \mathrm{mg} / \mathrm{ml} \mathrm{NBD-}$

398 cholesterol (Sigma, N2161) solubilized in 35\% $\beta$-cyclodextrin (Sigma, HZB1102) was added

399 and the mixture was incubated at $37^{\circ} \mathrm{C}$ for $2 \mathrm{~min}$. To start the enzymatic reaction, $1 \mu 12.5 \mathrm{mM}$

400 oleoyl-CoA (Sigma, O1012) was added and the reaction mixture was incubated at $37^{\circ} \mathrm{C}$ for 15

$401 \mathrm{~min}$. The reaction was terminated by adding 2:1 chloroform/methanol, the extract was separated

402 on an HPLC column at $0.2 \mathrm{ml} / \mathrm{min}$ (Agilent, Poroshell HPH-C18, $2.7 \mu \mathrm{m}$ ) running in 100\%

403 ethanol and detected via fluorescence detector on an HPLC (SHIMADZU). NBD-cholesterol

404 eluted at $1.3 \mathrm{~min}$ and its ester eluted at $1.9 \mathrm{~min}$. The peak areas of the NBD-cholesteryl ester

405 products and remaining NBD-cholesterol were integrated separately to obtain the relative ratio of

406 NBD-cholesterol that was converted into NBD-cholesteryl esters.

\section{Nanodisc preparation}

408 MSP2X was constructed by linking two MSP1E3D1 by PCR overlap extension, with Gly-Thr as

409 the linker. The MSP2X gene was constructed into a pET vector, with N-terminal His ${ }_{6}$ tag and

410 HRV 3C site. The MSP2X and MSP2N2 proteins were purified as described previously ${ }^{36}$. The

411 eluted SOAT1 protein in TBS buffer with $0.1 \%$ digitonin and $10 \mathrm{mM}$ desthiobiotin from strep- 
412 tactin column was concentrated by a 100-kDa cut-off ultrafiltration device (Millipore) and

413 exchanged into buffer without desthiobiotin. The SOAT1 protein was mixed with soybean polar

414 lipids extract (SPLE, Avanti) and purified MSP (MSP2N2 for SOAT1 tetramer, MSP2X for

415 SOAT1 dimer) at a molar ratio of SOAT1: MSP: SPLE $=1: 7: 100$. For the hSOAT1 dimer in

416 nanodisc that contained cholesterol, SPLE and cholesterol (at 4:1 ratio) were supplemented in

417 GDN detergent micelles. The SOAT1 protein was mixed with micelles and purified MSP2X at a

418 molar ratio of SOAT1: MSP2X: SPLE $=1: 4: 100$. After incubating at $4^{\circ} \mathrm{C}$ for 30 min, Bio-beads

$419 \mathrm{SM} 2$ (Bio-Rad) were added and rotated at $4^{\circ} \mathrm{C}$ for $1 \mathrm{~h}$ to initiate the reconstitution. Another batch

420 of fresh bio-beads was added and rotated at $4^{\circ} \mathrm{C}$ overnight. The next day, the Bio-beads were

421 removed and the mixture was loaded into a streptactin column to remove the empty nanodisc.

422 The eluted hSOAT1 in the nanodisc was concentrated and cleaved by prescission protease to

423 remove GFP tags. The nanodisc was centrifuged at 40,000 rpm for $30 \mathrm{~min}$, and then loaded onto

424 a superose-6 increase column running in TBS containing 0.5 mM TCEP. The collected fractions

425 were detected by SDS-PAGE and peak fractions were concentrated to $\mathrm{A}_{280}=1.2$. Because the

426 hSOAT1 tended to aggregate after nanodisc reconstitution, fractions of each peak were

427 combined and concentrated for cryo-EM grids preparations and only fractions containing high

428 ratio of SOAT1 dimer were used for data collection.

\section{Cryo-EM data collection}

430 The nanodisc samples were loaded onto glow-discharged GiG R1/1 holey carbon gold grids

431 (Lantuo) and plunged into liquid ethane by Vitrobot Mark IV (Thermo Fisher Scientific). Cryo-

432 grids were screened by Talos Arctica electron microscope (Thermo Fisher Scientific) operated at

433 the voltage of $200 \mathrm{kV}$ using a Ceta 16M camera (Thermo Fisher Scientific). Optimal grids were

434 transferred to Titan Krios electron microscope (Thermo Fisher Scientific) operated at the voltage 
436 per movie) were collected with a dose rate of $5.4 \mathrm{e}^{-} / \mathrm{pixel} / \mathrm{s}$ using $\mathrm{K} 2 \mathrm{Summit}$ direct electron

437 camera (Thermo Fisher Scientific) at a nominal magnification of $130,000 \times$, equivalently to a

438 calibrated super-resolution pixel size of $0.5225 \AA$, and with defocus ranging from $-1.3 \mu \mathrm{m}$ to -2.3

$439 \mu \mathrm{m}$. All data acquisition was performed automatically using SerialEM ${ }^{37}$.

\section{Cryo-EM image processing}

441 For the CI-976 complex, super-resolution movie stacks were motion-corrected, dose-weighted 442 and 2-fold binned by MotionCor2 1.1 .0 using $9 \times 9$ patches ${ }^{38}$. Micrographs with ice or ethane 443 contamination were manually removed. Contrast transfer function (CTF) parameters were 444 estimated using Gctf v1.06 ${ }^{39}$. Particles were picked by Gautomatch (developed by Kai Zhang) 445 and subjected to reference-free 2D classification. Unless otherwise stated, all classification and 446 reconstruction were performed with Relion $2.0^{40}$. Initial model was generated by cryoSPARC ${ }^{41}$ 447 using the selected particles from 2D classification. The selected particles were further subjected 448 to 3D classification using $\mathrm{C} 1$ symmetry. The particles selected from good 3D classes were re449 centered and their local CTF parameters were determined using Gctf v1.06. These particles were 450 further refined by cisTEM ${ }^{42}$ using C2 symmetry imposed. The resolution estimation was based 451 on the Part.FSC curve in cisTEM at FSC $=0.143$ cut-off. Local resolution estimation for hSOAT1 452 dimer and CI-976 complex was calculated using blocres ${ }^{43}$. For the apo state, images were 453 processed in the same way, except the finial refinement were done using Relion $3 .{ }^{44}$ with a soft 454 mask that excluded the MSP and lipids. The resolution estimations of apo state were based on 455 the gold standard FSC of 0.143 cut-off after correction of the masking effect ${ }^{45}$. Local resolution 456 estimation for hSOAT1 dimer in apo state was calculated using Resmap ${ }^{46}$.

\section{Model building and refinement}


The sharpened map in the presence of CI-976 from cisTEM were converted into mtz file by

459 Phenix ${ }^{47}$. The model was manually built de novo in Coot ${ }^{48}$. The assignment of transmembrane

460 domain helices were based on their connectivity aided by the less-sharpened map. The register

461 assignment and modeling building were based on the features of large aromatic side chains and

462 partly aided by the further sharpened map. The manually built model was refined by Phenix ${ }^{47}$.

463 The sterol-like ligand in non-protein density A was built as cholesterol for visualization. The

464 model in the presence of CI-976 were fitted into the map in the presence of BiSAS by Chimera ${ }^{49}$

465 and further refined by Phenix.

\section{Quantification and statistical analysis}

467 Global resolution estimations of cryo-EM density maps are based on the 0.143 Fourier Shell

468 Correlation criterion ${ }^{50}$. Fluorescence values were plotted versus the log of the concentration of

469 inhibitor, and GraphPad Prism 6 was used to generate a curve fit with dose-response inhibition

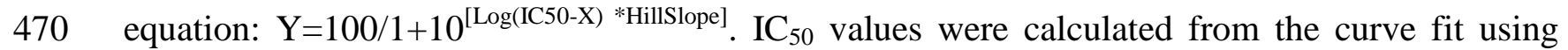

471 Prism software. The number of biological replicates $(\mathrm{N})$ and the relevant statistical parameters

472 for each experiment (such as mean or standard error) are described in the figure legends. No

473 statistical methods were used to pre-determine sample sizes.

\section{References:}

4761 Chang, C. C. Y., Sun, J. \& Chang, T.-Y. Membrane-bound O-acyltransferases (MBOATs). Frontiers in Biology 6, 177, doi:10.1007/s11515-011-1149-z (2011).

2 Chang, T. Y., Chang, C. C., Ohgami, N. \& Yamauchi, Y. Cholesterol sensing, trafficking, and esterification. Annu. Rev. Cell Dev. Biol. 22, 129-157, doi:10.1146/annurev.cellbio.22.010305.104656 (2006).

4813 Rogers, M. A. et al. Acyl-CoA:cholesterol acyltransferases (ACATs/SOATs): Enzymes with multiple sterols as substrates and as activators. J. Steroid Biochem. Mol. Biol. 151, 102-107, doi:10.1016/j.jsbmb.2014.09.008 (2015). 199, 61-73, doi:10.1016/j.chemphyslip.2016.04.006 (2016). 
4865 Levitan, I., Singh, D. K. \& Rosenhouse-Dantsker, A. Cholesterol binding to ion channels.

$487 \quad$ Front Physiol 5, 65, doi:10.3389/fphys.2014.00065 (2014).

4886 Shibuya, Y., Chang, C. C. \& Chang, T. Y. ACAT1/SOAT1 as a therapeutic target for Alzheimer's disease. Future Med Chem 7, 2451-2467, doi:10.4155/fmc.15.161 (2015).

Rong, J. X. et al. ACAT inhibition reduces the progression of preexisting, advanced atherosclerotic mouse lesions without plaque or systemic toxicity. Arterioscler. Thromb. Vasc. Biol. 33, 4-12, doi:10.1161/ATVBAHA.112.252056 (2013).

9 Yang, W. et al. Potentiating the antitumour response of CD8(+) T cells by modulating cholesterol metabolism. Nature 531, 651-655, doi:10.1038/nature17412 (2016).

10 Yue, S. et al. Cholesteryl ester accumulation induced by PTEN loss and PI3K/AKT activation underlies human prostate cancer aggressiveness. Cell Metab. 19, 393-406, doi:10.1016/j.cmet.2014.01.019 (2014).

11 Jiang, Y. et al. Proteomics identifies new therapeutic targets of early-stage hepatocellular carcinoma. Nature 567, 257-261, doi:10.1038/s41586-019-0987-8 (2019).

Hofmann, K. A superfamily of membrane-bound O-acyltransferases with implications for (2000).

13 Chang, C. C. et al. Immunological quantitation and localization of ACAT-1 and ACAT-2 in human liver and small intestine. J. Biol. Chem. 275, 28083-28092, doi:10.1074/jbc.M003927200 (2000).

14 Anderson, R. A. et al. Identification of a form of acyl-CoA:cholesterol acyltransferase specific to liver and intestine in nonhuman primates. J. Biol. Chem. 273, 26747-26754 (1998).

15 Field, F. J., Albright, E. \& Mathur, S. Inhibition of acylcoenzyme A: cholesterol acyltransferase activity by PD128042: effect on cholesterol metabolism and secretion in CaCo-2 cells. Lipids 26, 1-8 (1991). Ma, D. et al. Crystal structure of a membrane-bound O-acyltransferase. Nature 562, 286290, doi:10.1038/s41586-018-0568-2 (2018).

17 She, J. et al. Structural insights into the voltage and phospholipid activation of the mammalian TPC1 channel. Nature 556, 130-134, doi:10.1038/nature26139 (2018).

$18 \mathrm{Yu}, \mathrm{C}$. et al. Human acyl-CoA:cholesterol acyltransferase-1 is a homotetrameric enzyme in intact cells and in vitro. J. Biol. Chem. 274, 36139-36145 (1999).

$19 \mathrm{Yu}, \mathrm{C}$. et al. Role of the N-terminal hydrophilic domain of acyl-coenzyme A:cholesterol acyltransferase 1 on the enzyme's quaternary structure and catalytic efficiency. Biochemistry (Mosc.) 41, 3762-3769 (2002).

20 Lada, A. T. et al. Identification of ACAT1- and ACAT2-specific inhibitors using a novel, cell-based fluorescence assay: individual ACAT uniqueness. J. Lipid Res. 45, 378-386, doi:10.1194/jlr.D300037-JLR200 (2004).

21 Guo, Z. Y., Lin, S., Heinen, J. A., Chang, C. C. \& Chang, T. Y. The active site His-460 of human acyl-coenzyme A:cholesterol acyltransferase 1 resides in a hitherto undisclosed transmembrane domain. J. Biol. Chem. 280, 37814-37826, doi:10.1074/jbc.M508384200 (2005). 
Huang, L. H. et al. Acyl-coenzyme A:cholesterol acyltransferase 1 - significance of single-nucleotide polymorphism at residue 526 and the role of Pro347 near the fifth transmembrane domain. FEBS J. 281, 1773-1783, doi:10.1111/febs.12739 (2014).

23 Joyce, C. W. et al. ACAT1 and ACAT2 membrane topology segregates a serine residue essential for activity to opposite sides of the endoplasmic reticulum membrane. Mol. Biol. Cell 11, 3675-3687, doi:10.1091/mbc.11.11.3675 (2000).

24 Das, A., Davis, M. A. \& Rudel, L. L. Identification of putative active site residues of ACAT enzymes. J. Lipid Res. 49, 1770-1781, doi:10.1194/jlr.M800131-JLR200 (2008). Guo, Z. Y., Chang, C. C. \& Chang, T. Y. Functionality of the seventh and eighth transmembrane domains of acyl-coenzyme A:cholesterol acyltransferase 1. Biochemistry (Mosc.) 46, 10063-10071, doi:10.1021/bi7011367 (2007).

26 Lu, X., Lin, S., Chang, C. C. \& Chang, T. Y. Mutant acyl-coenzyme A:cholesterol

27 Guo, Z., Cromley, D., Billheimer, J. T. \& Sturley, S. L. Identification of potential

28 Chang, C. C., Huh, H. Y., Cadigan, K. M. \& Chang, T. Y. Molecular cloning and

29 Das, A., Davis, M. A., Tomoda, H., Omura, S. \& Rudel, L. L. Identification of the interaction site within acyl-CoA:cholesterol acyltransferase 2 for the isoform-specific inhibitor pyripyropene A. J. Biol. Chem. 283, 10453-10460, doi:10.1074/jbc.M709460200 (2008).

Chang, C. C. et al. Purification of recombinant acyl-coenzyme A:cholesterol acyltransferase 1 (ACAT1) from $\mathrm{H} 293$ cells and binding studies between the enzyme and substrates using difference intrinsic fluorescence spectroscopy. Biochemistry (Mosc.) 49, 9957-9963, doi:10.1021/bi1013936 (2010). Barnett, B. P. et al. Glucose and weight control in mice with a designed ghrelin Oacyltransferase inhibitor. Science 330, 1689-1692, doi:10.1126/science.1196154 (2010).

32 Rogers, M. A. et al. Cellular pregnenolone esterification by acyl-CoA:cholesterol acyltransferase. J. Biol. Chem. 287, 17483-17492, doi:10.1074/jbc.M111.331306 (2012).

33 Kawate, T. \& Gouaux, E. Fluorescence-detection size-exclusion chromatography for precrystallization screening of integral membrane proteins. Structure 14, 673-681, doi:10.1016/j.str.2006.01.013 (2006).

34 Goehring, A. et al. Screening and large-scale expression of membrane proteins in mammalian cells for structural studies. Nat. Protoc. 9, 2574-2585, doi:10.1038/nprot.2014.173 (2014). hydroxycholesterol as an allosteric activator for acyl-coenzyme A:cholesterol acyltransferase 1. J Biol Chem 278, 11642-11647, doi:10.1074/jbc.M211559200 (2003).

36 Ritchie, T. K. et al. Chapter 11 - Reconstitution of membrane proteins in phospholipid bilayer nanodiscs. Methods Enzymol 464, 211-231, doi:10.1016/S0076-6879(09)64011-8 (2009).

37 Mastronarde, D. N. Automated electron microscope tomography using robust prediction of specimen movements. J Struct Biol 152, 36-51, doi:10.1016/j.jsb.2005.07.007 (2005). 

improved cryo-electron microscopy. Nat Methods 14, 331-332, doi:10.1038/nmeth.4193 (2017).

39 Zhang, K. Gctf: Real-time CTF determination and correction. J. Struct. Biol. 193, 1-12, doi:10.1016/j.jsb.2015.11.003 (2016).

40 Kimanius, D., Forsberg, B. O., Scheres, S. H. W. \& Lindahl, E. Accelerated cryo-EM structure determination with parallelisation using GPUs in RELION-2. Elife 5, doi:ARTN e18722

10.7554/eLife.18722 (2016).

41 Punjani, A., Rubinstein, J. L., Fleet, D. J. \& Brubaker, M. A. cryoSPARC: algorithms for rapid unsupervised cryo-EM structure determination. Nat. Methods 14, 290-296, doi:10.1038/nmeth.4169 (2017).

42 Grant, T., Rohou, A. \& Grigorieff, N. cisTEM, user friendly software for single-particle image processing. Elife 7, doi:ARTN e35383

10.7554/eLife.35383 (2018).

43 Heymann, J. B. Guidelines for using Bsoft for high resolution reconstruction and validation of biomolecular structures from electron micrographs. Protein Sci. 27, 159-

601

602

603

604

605 171, doi:10.1002/pro.3293 (2018).

44 Zivanov, J. et al. New tools for automated high-resolution cryo-EM structure determination in RELION-3. Elife 7, doi:10.7554/eLife.42166 (2018).

45 Chen, S. X. et al. High-resolution noise substitution to measure overfitting and validate resolution in 3D structure determination by single particle electron cryomicroscopy. Ultramicroscopy 135, 24-35, doi:10.1016/j.ultramic.2013.06.004 (2013). Kucukelbir, A., Sigworth, F. J. \& Tagare, H. D. Quantifying the local resoluti
EM density maps. Nat. Methods 11, 63-65, doi:10.1038/nmeth.2727 (2014).

47 Adams, P. D. et al. PHENIX: a comprehensive Python-based system for macromolecular structure solution. Acta Crystallogr D 66, 213-221, doi:10.1107/S0907444909052925 (2010).

48 Emsley, P., Lohkamp, B., Scott, W. G. \& Cowtan, K. Features and development of Coot. Acta Crystallogr D 66, 486-501, doi:10.1107/S0907444910007493 (2010).

49 Pettersen, E. F. et al. UCSF Chimera--a visualization system for exploratory research and analysis. J Comput Chem 25, 1605-1612, doi:10.1002/jcc.20084 (2004).

50 Rosenthal, P. B. \& Henderson, R. Optimal determination of particle orientation, absolute hand, and contrast loss in single-particle electron cryomicroscopy. J Mol Biol 333, 721745, doi:DOI 10.1016/j.jmb.2003.07.013 (2003). 
bioRxiv preprint doi: https://doi.org/10.1101/2020.01.07.897124; this version posted January 8, 2020. The copyright holder for this preprint (which was not certified by peer review) is the author/funder, who has granted bioRxiv a license to display the preprint in perpetuity. It is made available under aCC-BY-NC-ND 4.0 International license.

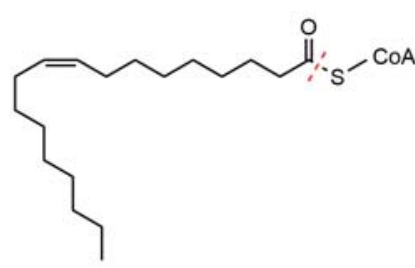

Oleoyl-CoA

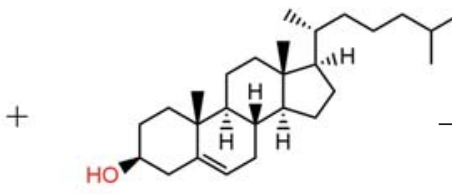

Cholesterol

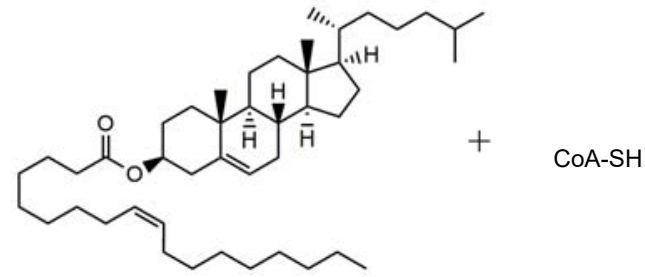

Cholesteryl-oleate b

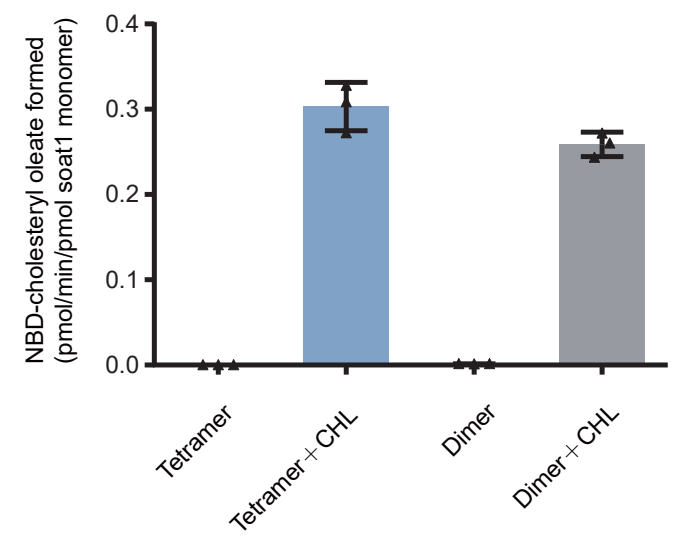

hSOAT1

C

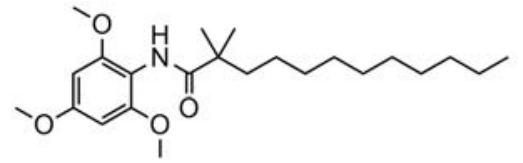

Cl-976

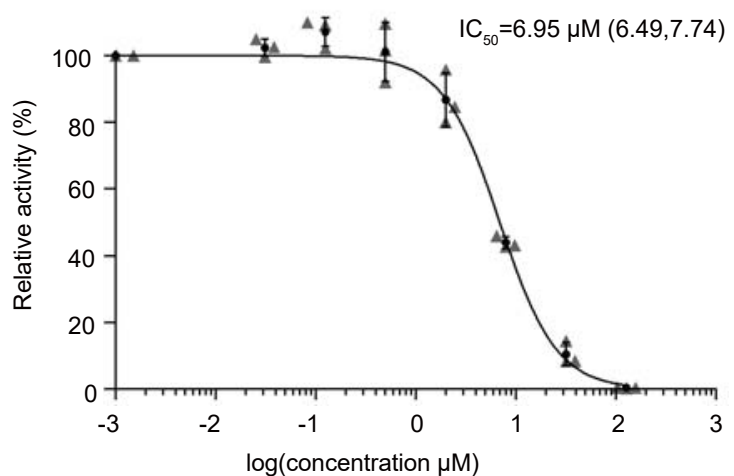

Fig. 1 The enzymatic reaction catalyzed by hSOAT1. a, Chemical structures of the substrates and products of hSOAT1 enzyme are shown. The red dashed line indicates the bond that is broken during acyl-transfer reaction. The hydroxyl group that accepts acyl group is highlighted in red. $\mathbf{b}$, The activation effect of cholesterol $(\mathrm{CHL})$ on the esterification reaction of NBD-cholesterol catalyzed by hSOAT1 tetramer and dimer (Data are shown as means \pm standard deviations, $\mathrm{n}=3$ biologically independent samples). c, Chemical structure of CI-976 and dose-dependent inhibition curve of hSOAT1 tetramer by CI-976 (The first data point is an artificial point. Data are shown as means \pm standard deviations, $\mathrm{n}=3$ biologically independent samples, and numbers in parentheses are the range for IC50 obtained from curve fitting). 
bioRxiv preprint doi: https://doi.org/10.1101/2020.01.07.897124; this version posted January 8, 2020. The copyright holder for this preprint (which was not certified by peer review) is the author/funder, who has granted bioRxiv a license to display the preprint in perpetuity. It is made
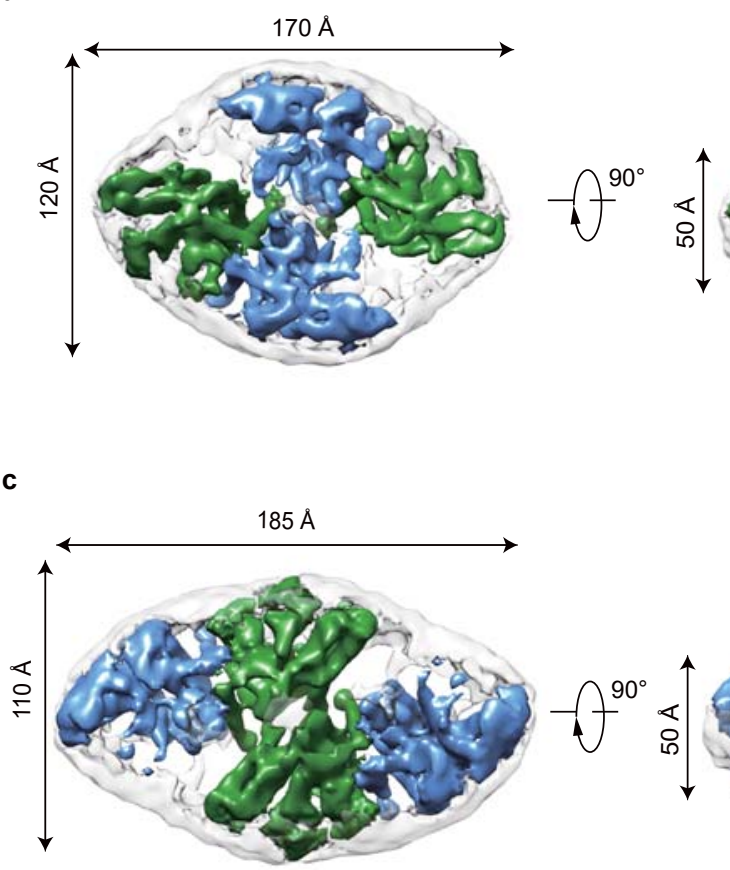

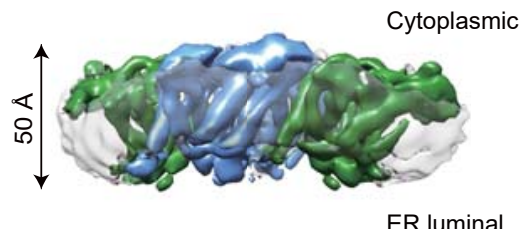

ER luminal b

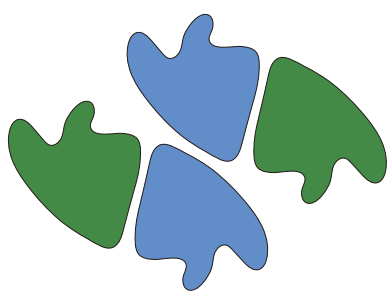

d

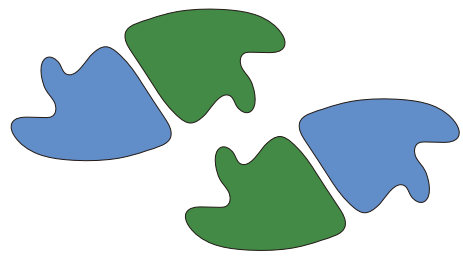

Fig. 2 Cryo-EM maps of the human SOAT1 tetramer. a, Cryo-EM density map of the oval-shaped hSOAT1 tetramer in top view and side view. Two subunits in one hSOAT1 dimer are colored in green and blue, respectively. Densities of the MSP and lipids in nanodiscs are colored in gray with semi-transparency. b, The domain arrangement of oval-shaped hSOAT1 tetramer is shown in a cartoon model in top view. Each subunit is colored the same as in (a). c, The density map of the rhombic-shaped hSOAT1 tetramer is shown in top and side view. d, The domain arrangement of rhombic-shaped hSOAT1 tetramer in top view. Each subunit is colored in the same way as in (c). 
bioRxiv preprint doi: https://doi.org/10.1101/2020.01.07.897124; this version posted January 8, 2020. The copyright holder for this preprint (which was not certified by peer review) is the author/funder, who has granted bioRxiv a license to display the preprint in perpetuity. It is made available under aCC-BY-NC-ND 4.0 International license.

a

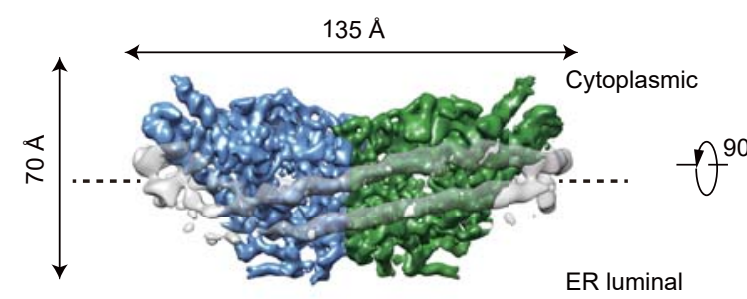

b

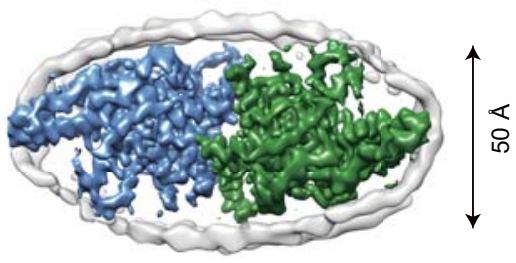

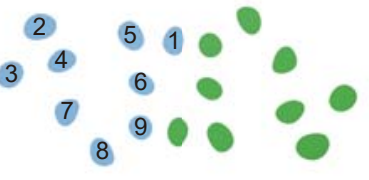

c

Cytoplasmic

e
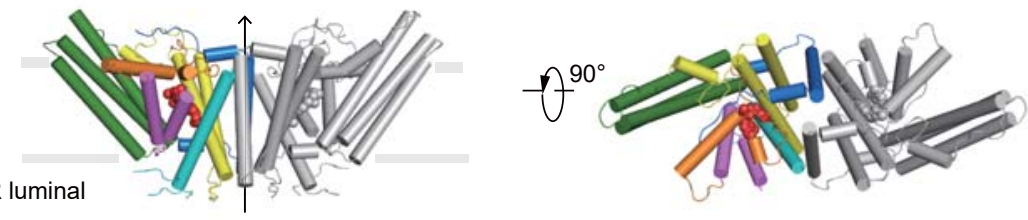

Cytoplasmic

ER luminal

DItC

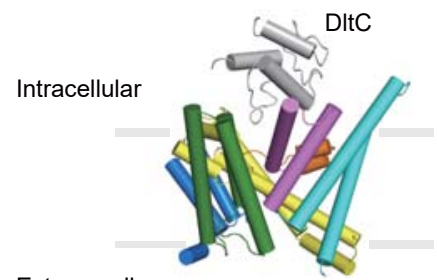

DItB
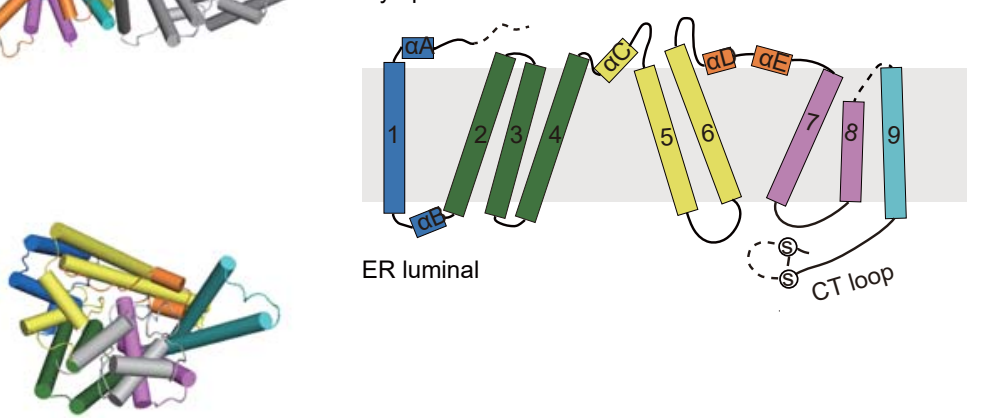

Extracecullar

Fig. 3 The structure of hSOAT1 dimer. a, Cryo-EM map of hSOAT1 dimer in side view and top view. Two subunits of the dimer are colored in green and blue. Density corresponding to the nanodisc is colored in gray with semi-transparency. b. Top view of the cross-section of the transmembrane domain at the approximate level indicated by the dashed lines in (a). The identities of the transmembrane helices from the blue subunit are labeled in numbers. c, The structural models of hSOAT1 dimer are shown in side view and top view. Helices are shown as cylinders. One subunit of hSOAT1 is in rainbow color and the other subunit is in grey. CI-976 molecule is shown as red spheres. d, The topology of one hSOAT1 subunit. The colors are used in the same way as in (c). e, The crystal structure of DltB-DltC complex in side view and top view (PDB ID: 6BUG). The DltB subunit is in rainbow color while the DltC subunit is in gray. 
bioRxiv preprint doi: https://doi.org/10.1101/2020.01.07.897124; this version posted January 8, 2020. The copyright holder for this preprint (which was not certified by peer review) is the author/funder, who has granted bioRxiv a license to display the preprint in perpetuity. It is made available under aCC-BY-NC-ND 4.0 International license.
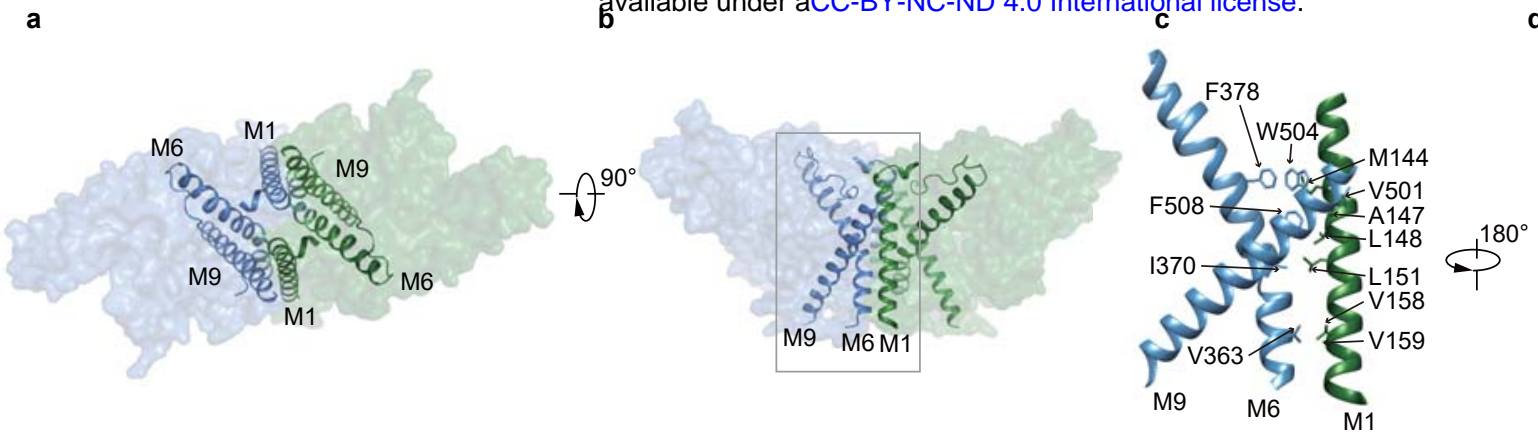

Fig. 4 | The dimer interface of hSOAT1 dimer. a-b, Top view and side view of one hSOAT1 dimer are shown in surface representation with semi-transparency. M1, M6 and M9 helices are shown as ribbons. c, Close-up view of the dimer interface boxed in (b), with interacting residues shown in sticks. $\mathbf{d}$, A $180^{\circ}$ rotated view compared to (c). 
bioRxiv preprint doi: https://doi.org/10.1101/2020 01,07.897124; this version posted January 8, 2020. The copyright holder for this preprint (which was not certified by peer review) is the authof/funder, who has granted bioRxiv a license to display the preprint in perpetuity. It is made
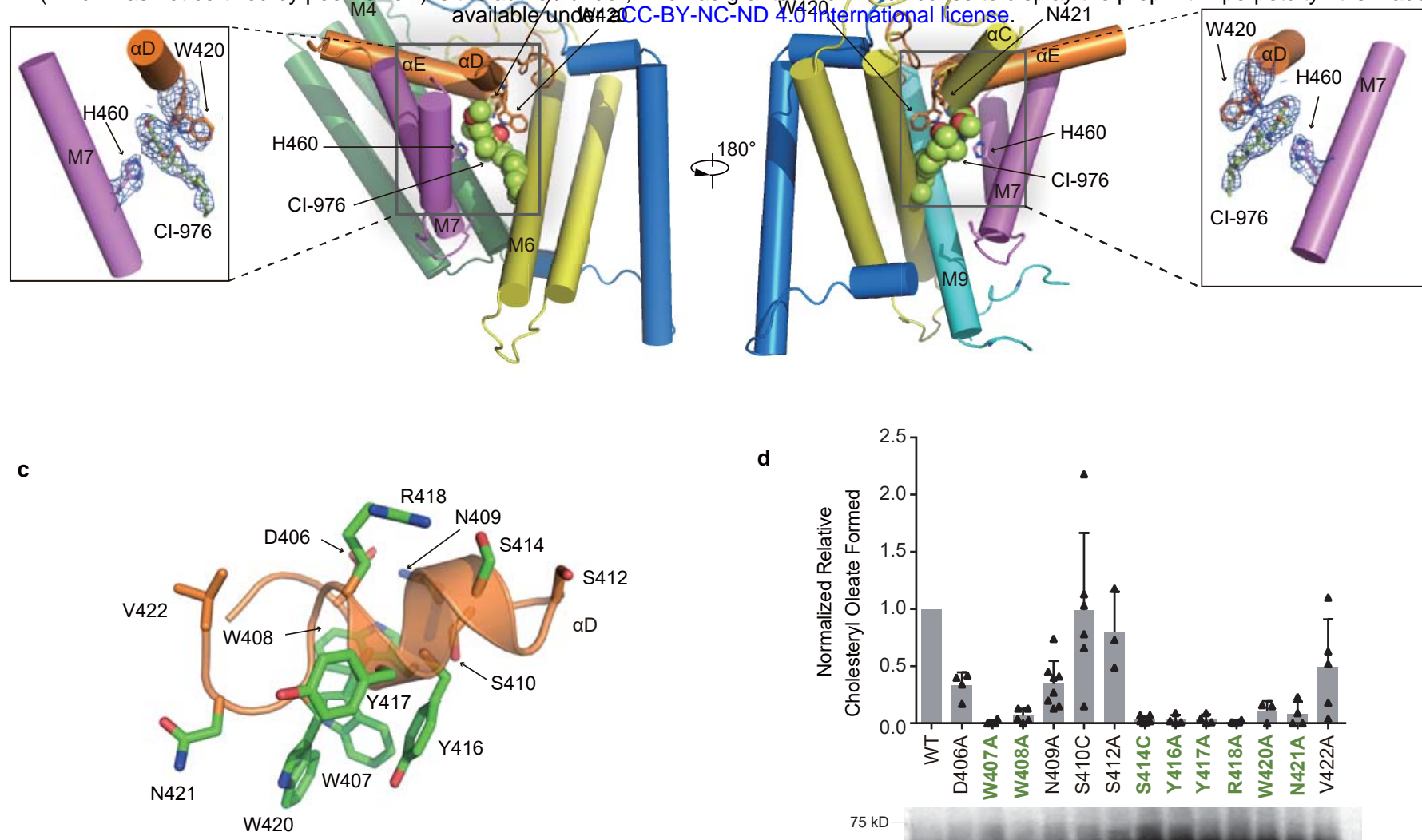

d
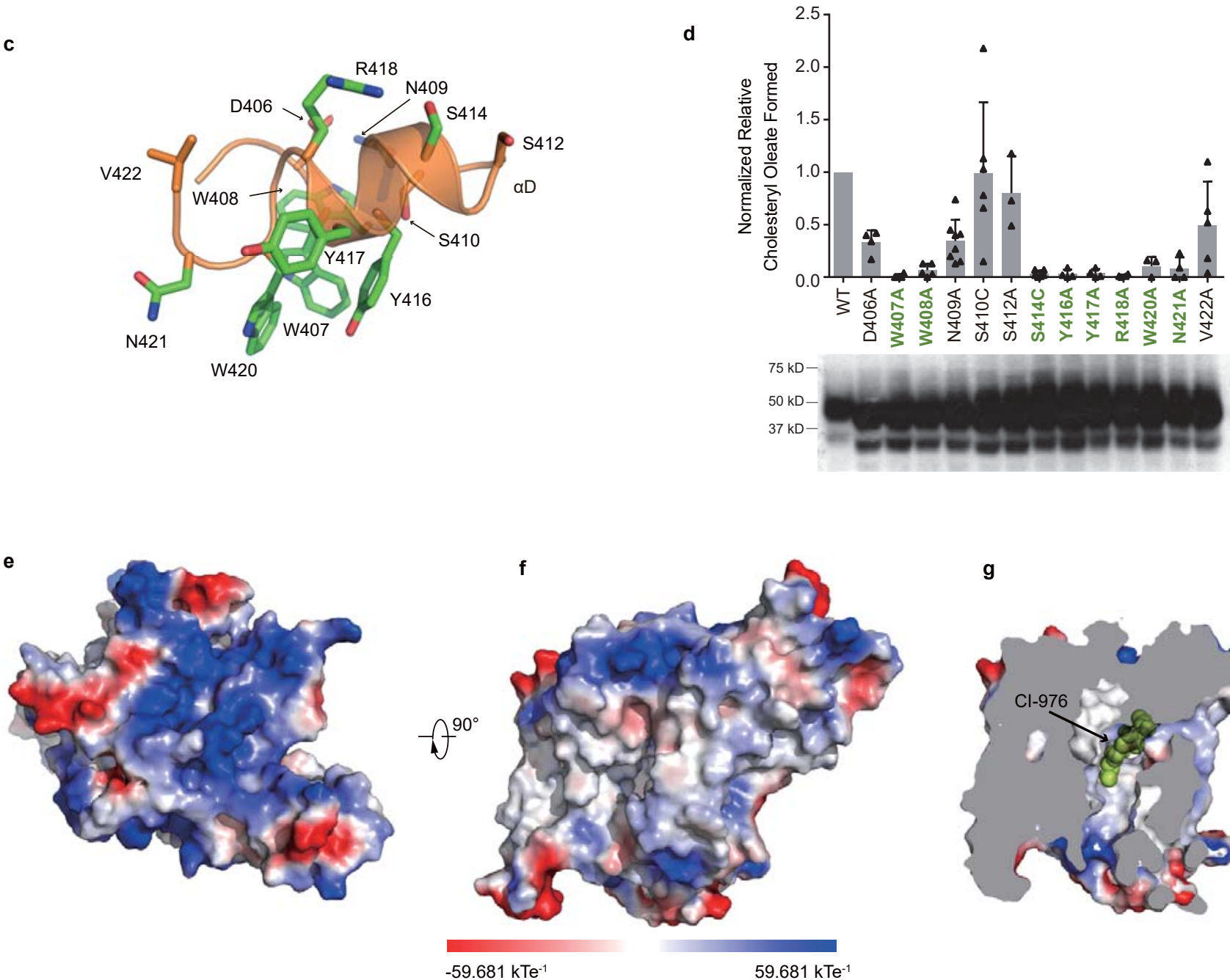

g

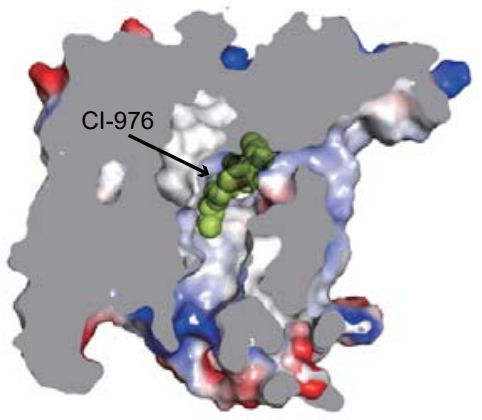

Fig. 5 The catalytic chamber and the CI-976 binding site in hSOAT1. a-b, Side views of one hSOAT1 subunit in cartoon representation. The transmembrane helices are colored in the same way as in Fig. 3c, and 3d. The inhibitor CI-976 is shown in lemon sphere. The side chains of residues that are close to CI-976 are shown in sticks. In the inlet, the cryo-EM densities of CI-976 and adjacent side chains were shown in blue meshes at the same contour level. Maps were further sharpened at -50 $\AA$ by Coot for visualization. c, Close-up view of the M6- $\alpha \mathrm{D}$ loop and $\alpha \mathrm{D}$ with side chains shown in sticks. Residues that are important for SOAT1 enzyme activity reported in (d) were colored in green. $\mathbf{d}$, Enzymatic activities of various hSOAT1 mutants. (For D406A, n=4. For W407A, n=4. For W408A, n=5. For N409A, n=8. For S410C, $n=6$. For S412A, $n=3$. For S414C, $n=6$. For Y416A, $n=4$. For Y417A, $n=4$. For R418A, $n=4$. For W420A, $n=3$. For N421A, $n=4$. For V422A, $n=5$.) Data are shown as means \pm standard errors. A two-tailed unpaired $t$ test was used to calculate the $\mathrm{p}$ values. For S410C, $\mathrm{p}=0.9434$. For $\mathrm{S} 412 \mathrm{~A}, \mathrm{p}=0.017$. Other mutants had $\mathrm{p}$ values less than 0.0001 . The bottom showed the western results of the hSOAT1 mutants proteins. e-f, The top and side views of one hSOAT1 monomer in the surface representation. The surfaces are colored by electrostatic potential calculated by Pymol. $\mathbf{g}$, The cut-away view showing the binding pocket of the inhibitor CI-976 inside the reaction chamber. 
bioRxiv preprint doi: httes: (which was not certified bepeer review) is the author/funder, who has gramtedobidRxiv a license to display the preprint in perpetuity. It is made
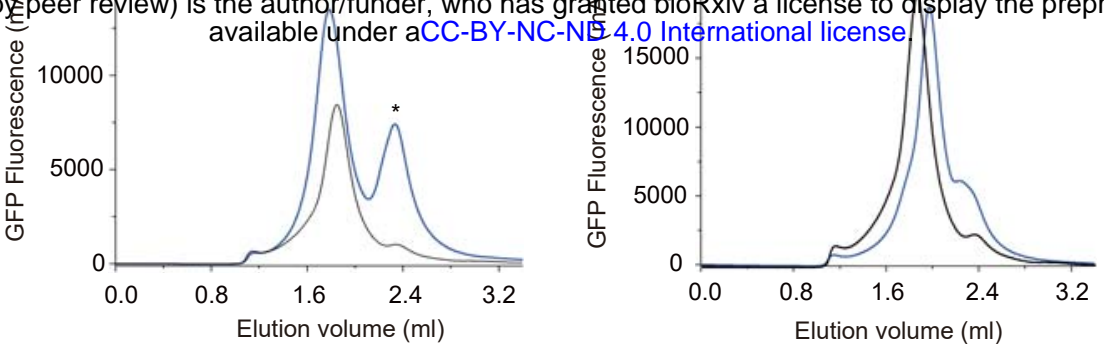

C

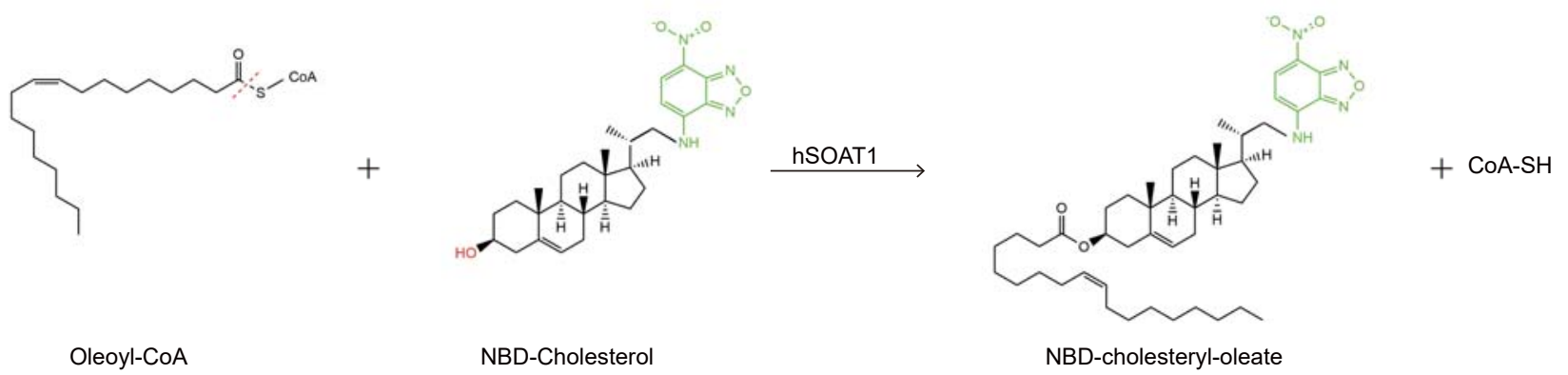

d

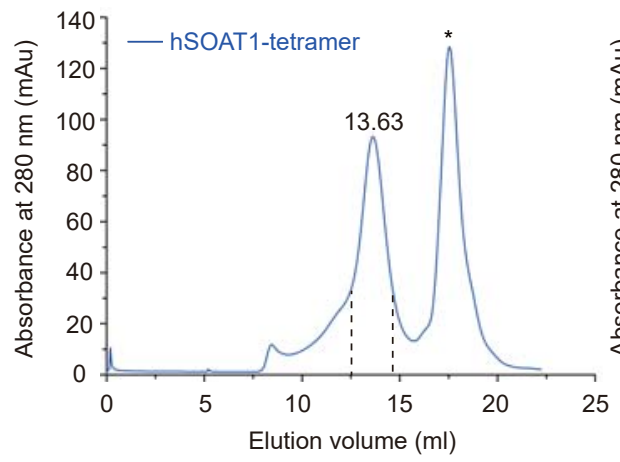

g

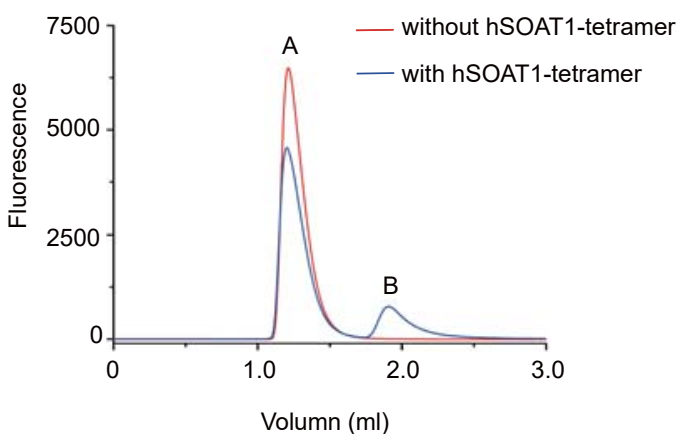

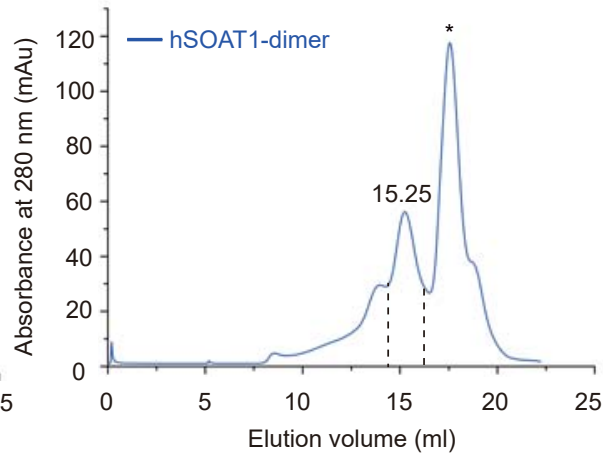

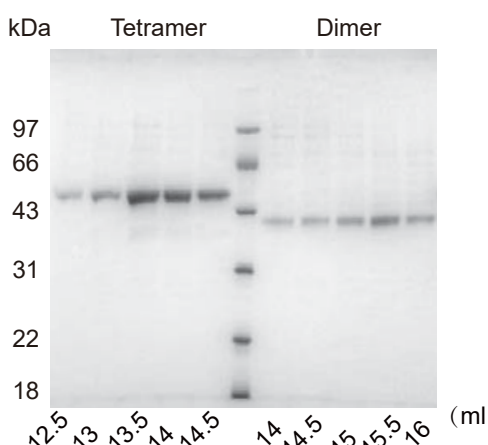

h

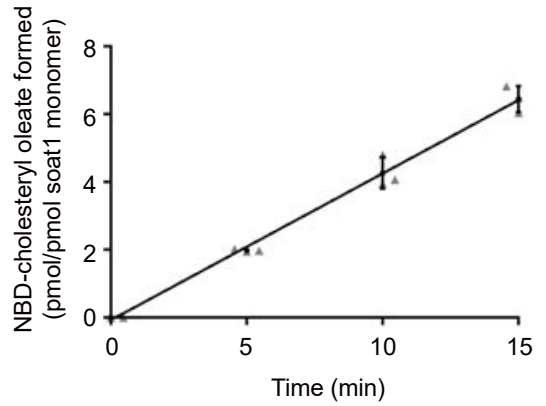

Fig. S1 | Characterization of human SOAT1 proteins. a-b, Fluorescence-detection size-exclusion chromatography (FSEC) traces of the N-terminal GFP tagged hSOAT1 tetramer and dimer on a Superose 6 increase column. The traces of C-terminal GFP tagged mouse TPC1 were shown in black. The NGFP-hSOAT1 tetramer protein elutes at a position slightly earlier than the dimeric mTPC1-CGFP, while the NGFP-hSOAT1 dimer protein elutes later than the mTPC1-CGFP. An asterisk denotes the position of free GFP. c, The chemical reaction of hSOAT1 activity assay using NBD-cholesterol as substrate. The red dashed line indicates the bond that is broken during acyltransfer reaction, the hydroxyl group that forms ester bond with the acyl group is highlighted in red. The NBD-fluorescent group is colored in green. d-e, The superose 6 elution profiles of hSOAT1 tetramer (d) and dimer (e), the fractions between the dashes were pooled and used for SDS-PAGE analysis. An asterisk denotes the position of GFP. f, The SDS-PAGE gel of purified hSOAT1 tetramer and dimer. g, The separation of NBD-cholesterol and NBD-cholesteryl-oleate by HPLC. Peak A is the free NBDcholesterol. Peak B is the NBD-cholesteryl-oleate product. The fraction of NBD-cholesteryl-oleate product was calculated as area A/(area A+ area B). h, The reaction of hSOAT1 tetramer was linear with time within the first 15 min (Data are shown as means \pm standard deviations, $\mathrm{n}=3$ biologically independent samples). 
a

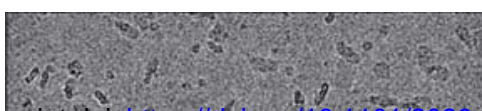

bioRxiv preprint doi: https://oi.org/10.1101\%2020.01.07.897124; this version posted (which was not certified by peer review) is the author/funder, who has granted bioRxiv

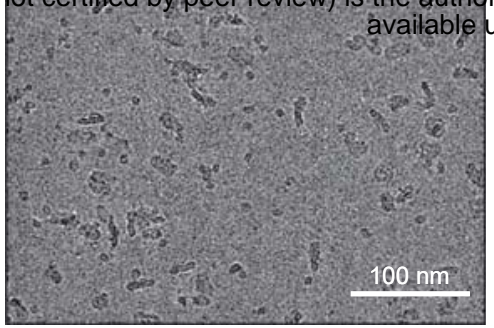

C

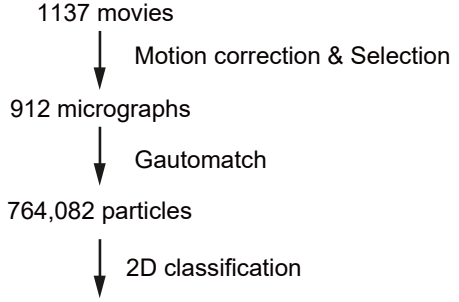

764,082 particles

2D classification

59,517 particles

$3 \mathrm{D}$ classification with $\mathrm{C} 1$
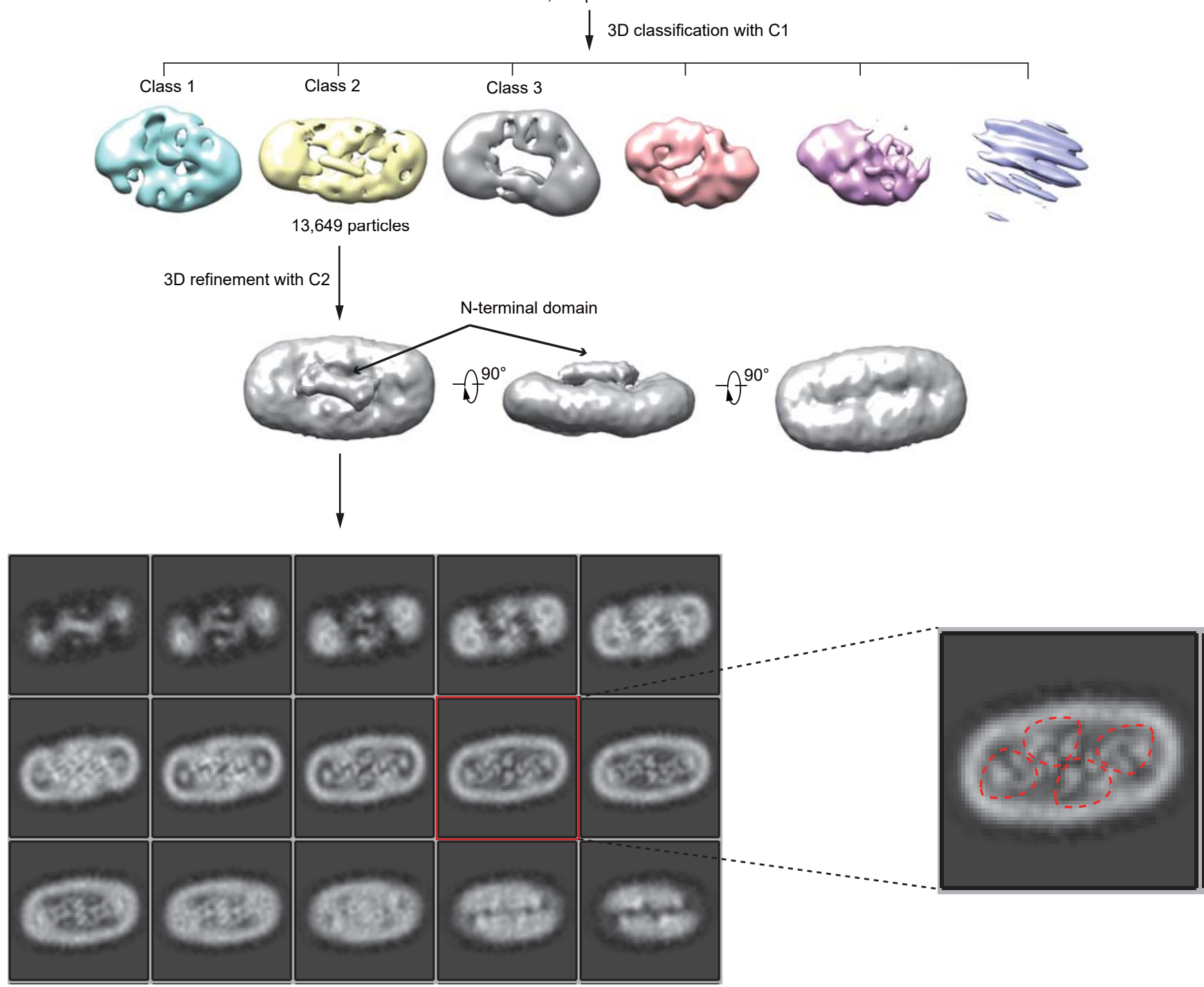

Fig. S2 | Cryo-EM image processing procedure of the hSOAT1 tetramer in digitonin detergent. a, Representative raw micrograph of hSOAT1 tetramer sample. b, Representative 2D class averages of the cryo-EM particles of hSOAT1 tetramer. c, Flowchart of the image processing procedure for hSOAT1 tetramer. d, The top-down slice view of the 3D density map after 3D refinement and postprocessing. The slice in red box is zoomed in for visualization. The red dashes circle each individual hSOAT1 monomer. 
bioRxiv preprint doi: https://doi.org/10.1101/2020.01.07.897124; this version posted January 8, 2020. The copyright holder for this preprint (which was not certified by peer review) is the author/funder, who has grantegd bioRxiv a license to display the preprint in perpetuity. It is made

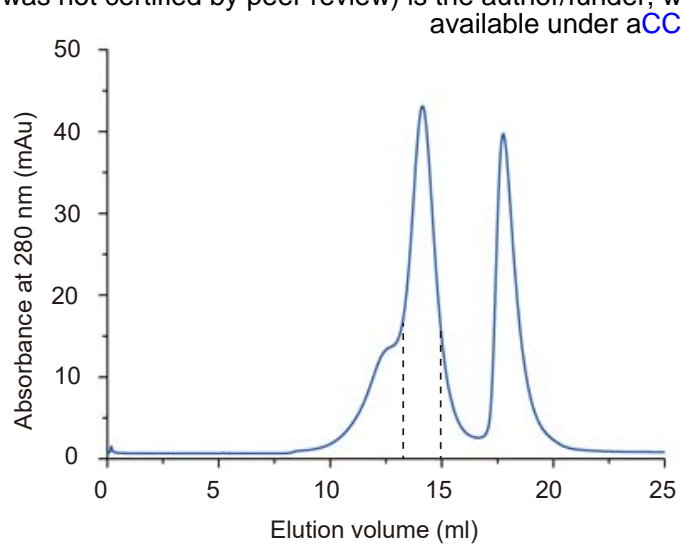

c

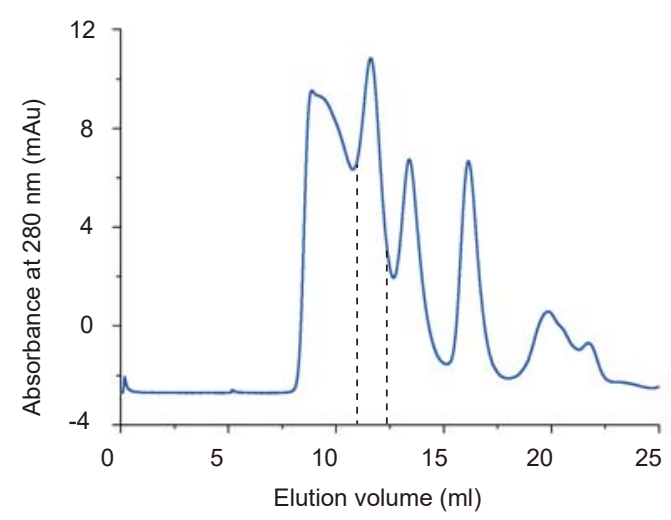

d
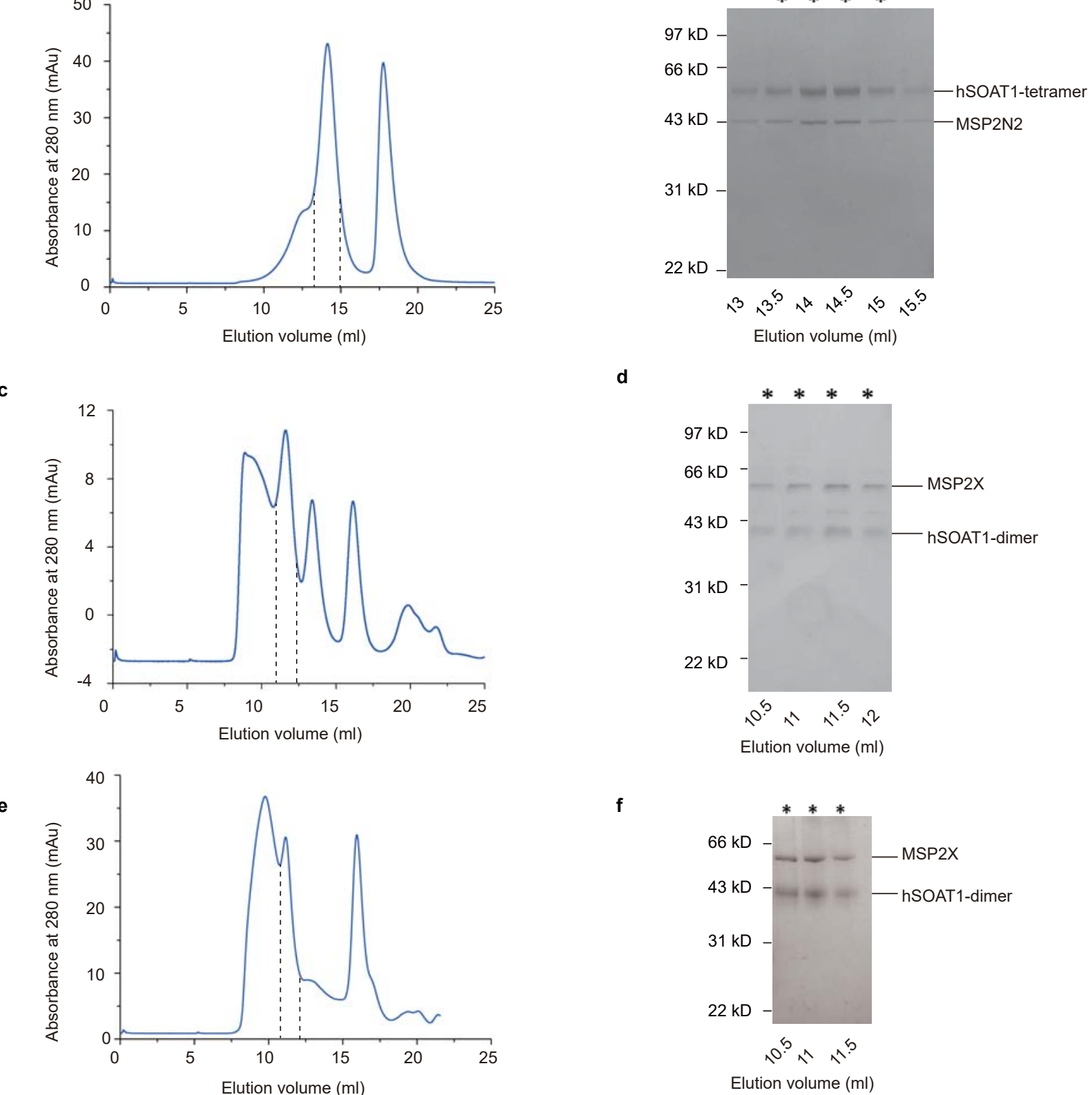

f

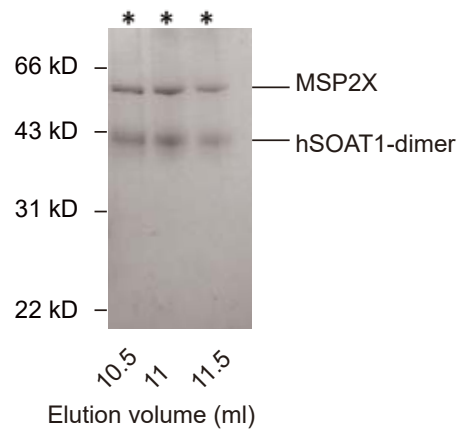

Fig. S3 | Purification of hSOAT1 tetramer and dimer nanodisc samples. a, Size exclusion chromatography (SEC) profile of the hSOAT1 tetramer nanodisc sample on Superose 6 . The fractions between the dashes were pooled and used for cryo-EM analysis. b, hSOAT1 tetramer nanodisc samples of the indicated SEC fractions were subjected to SDS-PAGE and Coomassie blue staining. The asterisks denote the pooled fractions. c-d, Superdex 200 SEC profiles and SDS-PAGE of hSOAT1 dimer nanodisc in the presence of CI-976. e-f, SEC and SDS-PAGE results of hSOAT1 dimer nanodisc in the presence of cholesterol and BiSAS 
hioRxiv preprint doi: https://doi.org/10.1101/2020.01.07.897124; this verojon posted January 8, 2020. The copyright holder for this preprint (which was not certified by peer review) is the author/funder, who has granted bioRxiv a license to display the preprint in perpetuity. It is made
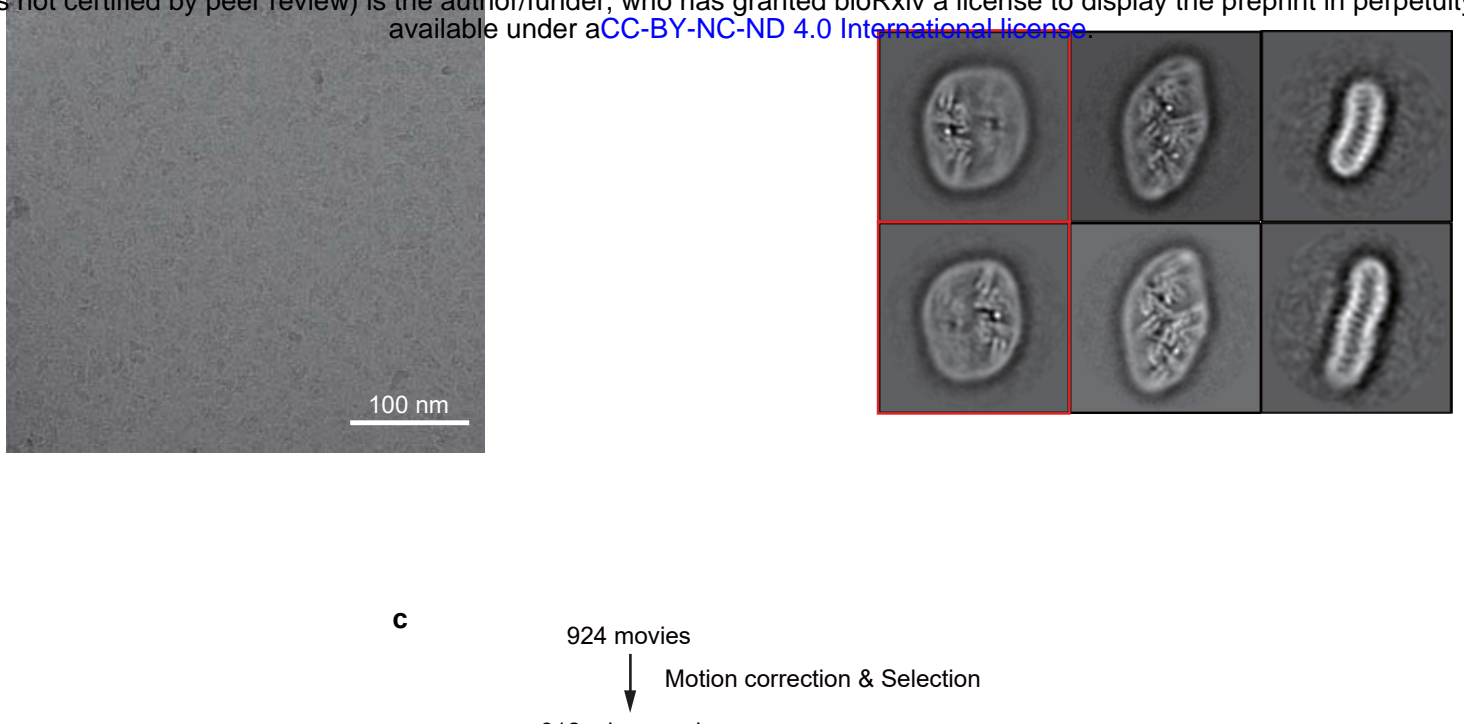

912 micrographs

Gautomatch

210,607 particles

$\downarrow 2 \mathrm{D}$ classification

82,445 particles

3D classification

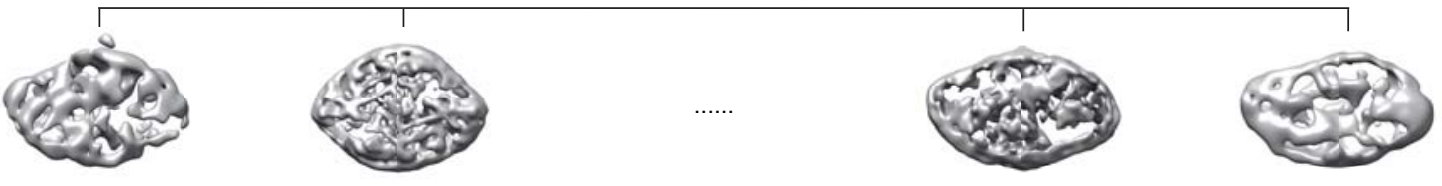

21,985 particles

13,703 particles
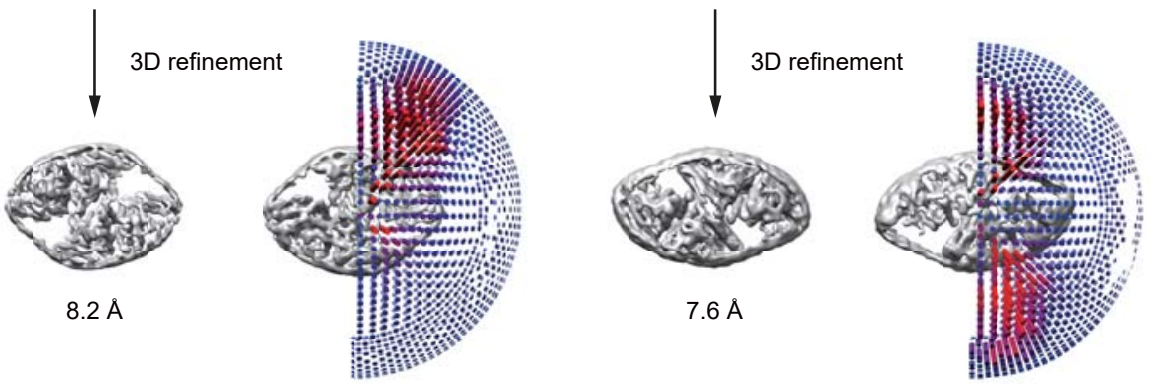

d

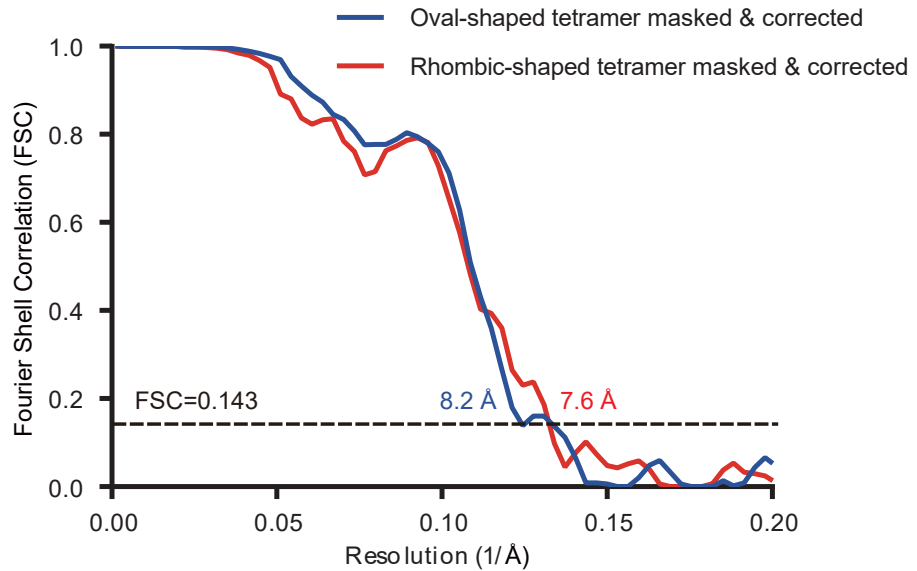

Fig. S4 | Cryo-EM image processing procedure of the hSOAT1 tetramer. a, Representative raw micrograph of hSOAT1 tetramer sample. b, Representative 2D class averages of the cryo-EM particles of hSOAT1 tetramer. The 2D class averages in red boxes show one clear dimer in adjacent to a blurry dimer, indicating the highly mobile interface between dimers. c, Flowchart of the image processing procedure for hSOAT1 tetramer. d, Gold-standard Fourier shell correlation (FSC) curves of the final refined maps for oval-shaped tetramer (blue line) and rhombic-shaped tetramer (red line). Resolution estimations ( $8.2 \AA$ for the oval-shaped tetramer and $7.6 \AA$ for the rhombic-shaped tetramer) are based on the criterion of an FSC cutoff of 0.143 
bioRxiv preprint doi: https://doi.org/10.1101/2020.01.07.897124; this version posted January 8, 2020. The copyright holder for this preprint Pwhich was not certified by peer review) is the author/funder, who has Granted bioRxiv a license to display the preprint in perpetuity. It is made
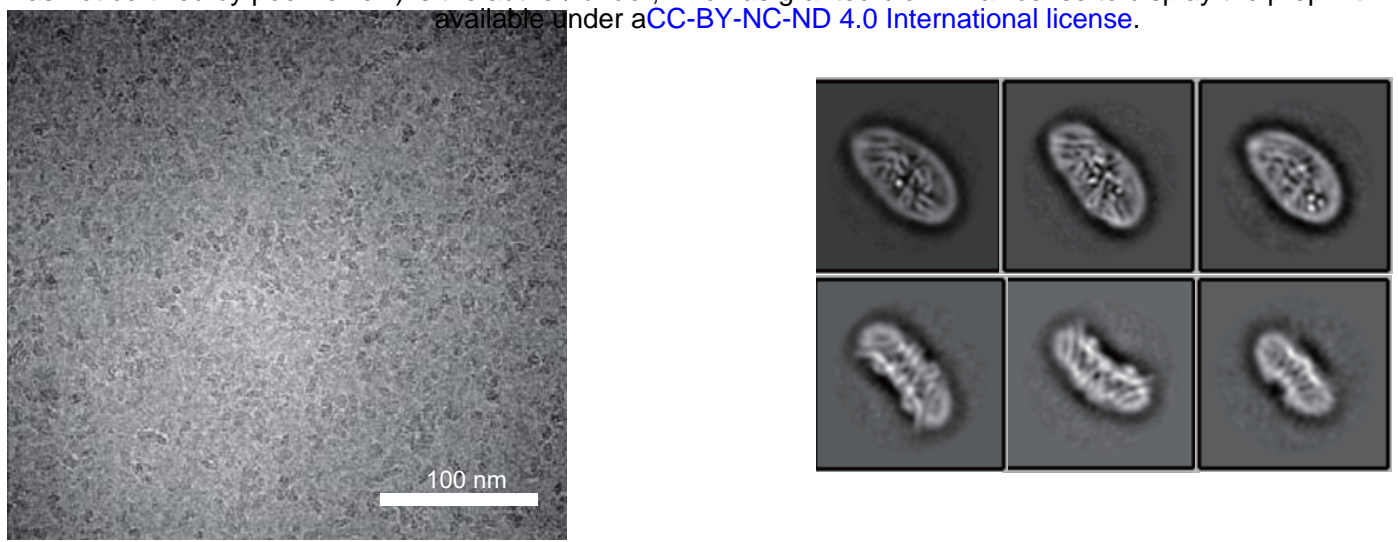

c nder aCC-BY-NC-ND 4.0 International license.

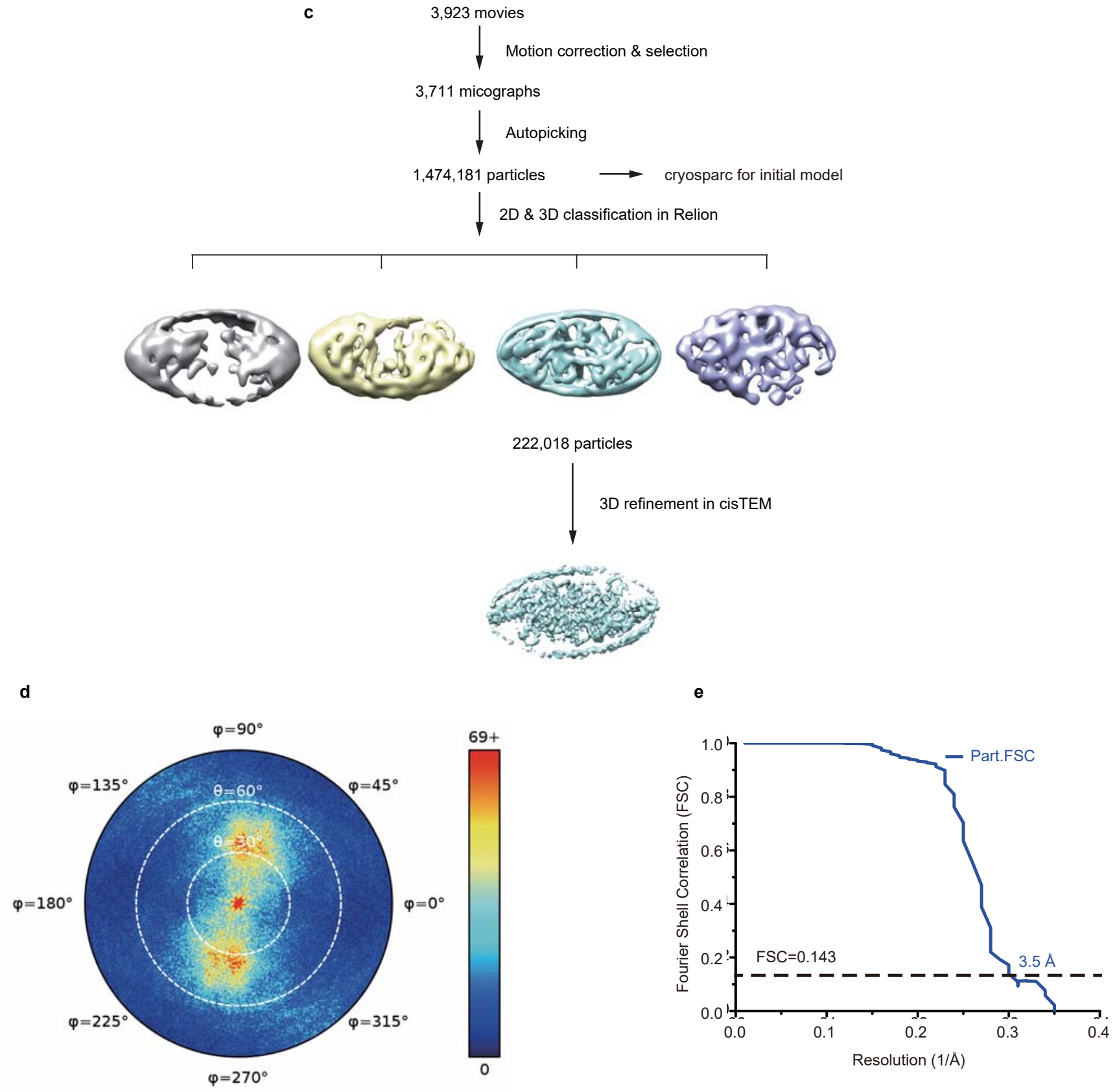

Fig. S5 | Cryo-EM image processing procedure of the hSOAT1 dimer in complex with CI-976. a, Representative raw micrograph of hSOAT1 dimer. b, Representative 2D class averages of the cryo-EM particles of hSOAT1 dimer. c, Flowchart of the image processing procedure for hSOAT1 dimer. d, Angular distribution of the final reconstruction of hSOAT1 dimer. e, Gold-standard Fourier shell correlation (FSC) curve of the final refined map for hSOAT1 dimer. Resolution estimation ( $3.5 \AA$ ) is based on the criterion of the FSC cutoff at 0.143 in cisTEM. 
a bioRxiv preprint doi: https://doi.org/10.1101/2020.01.07.897124; this version posted January 8, 2020. The copyright holder for this preprint (which was not certified by peer review) is the author/funder, who has granted bioRxiv a license to display the preprint in perpetuity. It is made available under aCC-BY-NC-ND 4.0 International license.
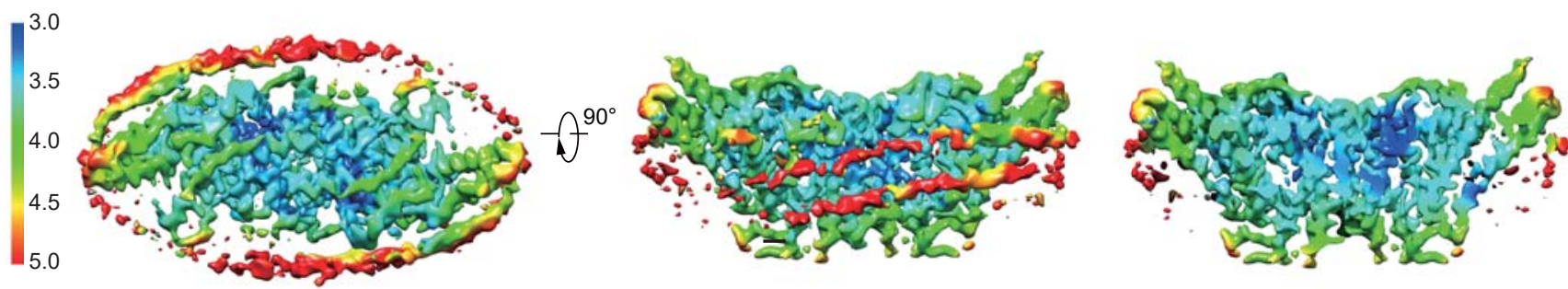

b

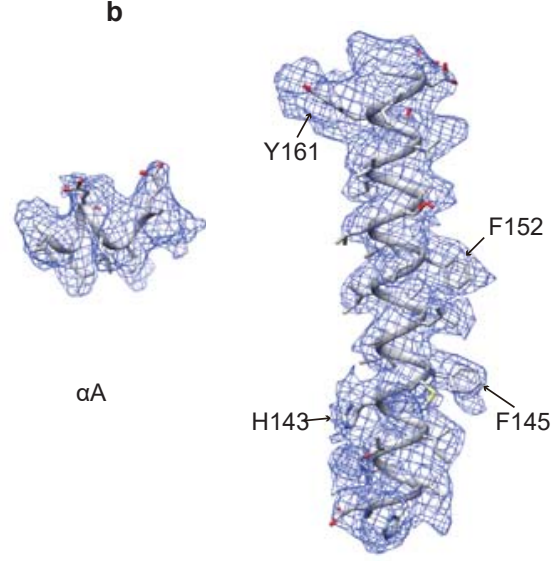

M1

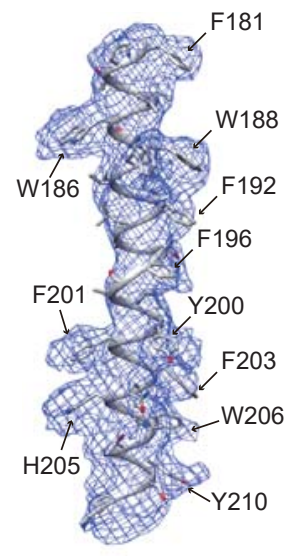

M2

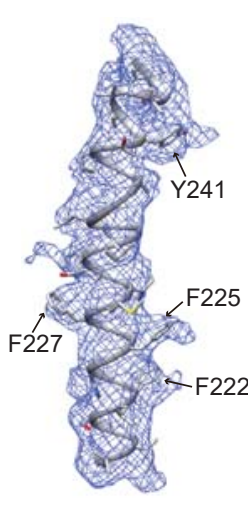

M3

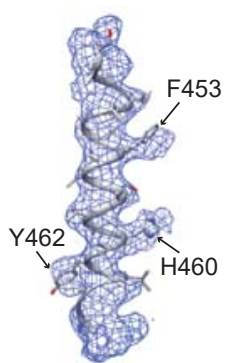

M7
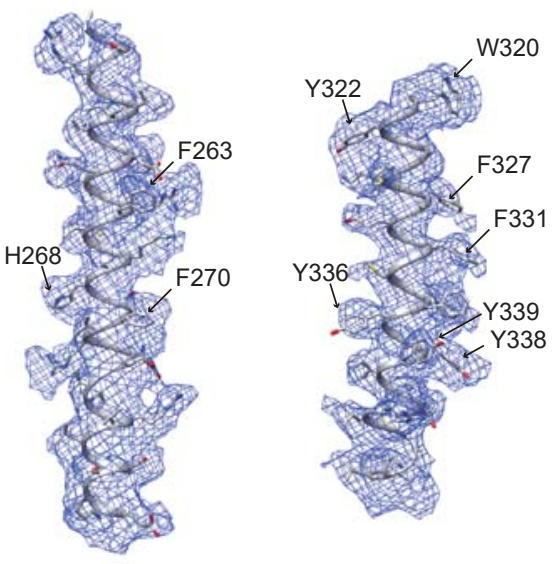

M4

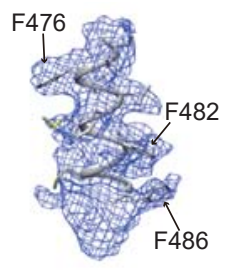

M8

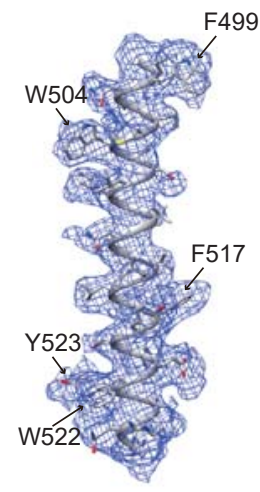

M9

Fig. S6 | Electron density map of the hSOAT1 dimer in complex with CI-976. a, Top view (left), side view (middle) and cut-away (right) representations of the hSOAT1 dimer cryo-EM density map colored according to the local resolution estimation. b, EM density segments (blue mesh) of the 9 transmembrane helices (M1-M9), $\alpha \mathrm{A}$ and $\alpha \mathrm{D}-\alpha \mathrm{E}$, . 
bioRxiv preprint doi: https://doi.org/10.1101/2020.01.07.897124; this version posted January 8, 2020. The copyright holder for this preprint (which was not certified by peer review) is the author/funder, who has granted bioRxiv a license to display the preprint in perpetuity. It is made available under aCC-BY-NC-ND 4.0 International license.

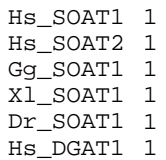

-------MVGEEKMSLRNRLSKSRE---NPEEDE-DQRNPAKESLETPSNGRIDIKQLIAKKIKLTAEAEELKPFFMKEVGSHFDDFVTNLIEKSASLDN 89 --------MEPGGARLRLQRTEG----LGGER-ERQPCGDGNTET--------HRAPDLVQWTRHMEAVKAQLLEQAQGQLRELLDRAMREAIQSYP 76 MKALFVVAAMAGEDCVRKRPSGSTTTYKSPENEEMQRRPDGDRSFQNSSNGRVDVDHVITRKMQLIAEAEQLKPVFMKEVDSHFTEFVNSLVAKSALLDS 100 ------MSDEEGRVLRSRRLISKQSVHSEQEDV-ARRTEGDRVFRS--NGLVDLEHVINRKMEMRKKAEHLKNELMKEVDGHLNEFVNNLIEESTVLES 90 ------MVNEGAGGPRSRKSSHKV---ASSSDK-DGPERDAEEFPLSSNGKVEVEQI ISAKLQLKKKAEHLKADLMRQFDAQVNEFMDSLIEESASLGS 89 -

M1 $\alpha \mathrm{B}$

HS_SOAT1 90 GGCALTTFSVLEGEKNNHRAKDLRAPPEQGKIFIARRSLIDELIEVD----HIRTIYHMFIALLILFILSTLVVDYIDEGRLVLEFSLLSYAFGKFPTVV 185 HS_SOAT2 77 SQDK-PLPPPPPG----SLSRTQEPSLGKQKVFIIRKSLLDELMEVQ----HFRTIYHMF IAGLCVFIISTLAIDF IDEGRLLLEFDLLIFSFGQLPLAL 167 Gg_SOAT1 101 SSSA-SLFPASCSEKELHKAKALRAPPEHGKIFTARRSLIDELFEVS----HIRTIYHMFIALLIVF ILSTLLVDF IDEGRLVLGFDLLVYVFGKFPVVF 195 Xl_SOAT1 91 MSAA---PSSGNVEKDSNKLRGLRAPPEHGKLFVSRRSLLDELFEVN----HIRTIYHMFIALLILFILSTLVVDCIDEGRLVLEFDLLVYAFGKFPIVI 183 Hs_DGAT1 40 VGAAGDAPAPAPN-------KDGDAGVGSGHWELRCHRLEDSLF SSDSGF SNYRGILNWCVVMLILSNARLFLENLIKYGILVDPIQVVSL-FLKDPYS- 130

M2 M3

M4

HS_SOAT1 186 WTWWIMFLST---FSVPYFLFQHWATGYSKSSHPLIRSLFHGFLFMIFQIGVLGFGPTYVVLAYTLPPASRFIIIFEQIRFVMKAHSF------VRENVP 276 HS_SOAT2 168 VTWVPMFLST---LLAPYQALRLWARGTWTQATGL------GCALLAAHAVVLCALPVHVAVEHQLPPASRCVLVFEQVRFLMKSYSF------LREAVP 252 (1) Dr_SOAT1 183 VTWMCMFLST---LVVPYVLLVVWAGIYSSSQHRLLWTVLAGSILLIYQGLGLGFLPTYVVLKNGLPPASCFILILEQVRLMMKSHSF------IRENVP 273 HS_DGAT1 131 WPAPCLVIAANVFAVAAFQVEKRLAVGALTEQAGLL-------LHVANLATILCFPAAVVLLVESITPVGSLLALMAHTILFLKLFSYRDVNSWCRRARA 223

\begin{tabular}{lllll}
\cline { 3 - 4 } & &
\end{tabular}
M6 $\alpha \mathrm{D}$ $\alpha \mathrm{E}$ M7 HS_SOAT1 362 LVLCVFNSILPGVLILFLTFFAFLHCWLNAFAEMLRFGDRMFYKDWWNSTSYSNYYRTWNVVVHDWLYYYAYKDFLWFFSKRFKSAAMLAVFAVSAVVHE 461 Hs_SOAT2 336 LVLSILHATLPGIFMLLLIFFAFLHCWLNAFAEMLRFGDRMFYRDWWNSTSF SNYYRTWNVVVHDWLYSYVYQDGLRLLGARARGVAMLGVFLVSAVAHE 435 Gg_SOAT1 372 LVLCIFNSILPGVLILFLVFFAFLHCWLNAFAEMMRFADRMFYKDWWNSTSYANYYRTWNVVVHDWLYYYAYRDFLWFFGKKFKAAAMLSVFTVSAAVHE 471 X1_SOAT1 360 LVLCIFNSILP GVLVLFLAFFAFLHCWLNAFAEMLRFADRMFYKDWWNSTSFANYYRTWNVVVHDWLYYYAYRDFLWFLGRRFKAAAMLFVFTVSAVVHE 459 Dr_SOAT1 359 MVLCVFNSILPGVLVLFLAFFAFLHCWLNAFAEMLRFGDRMFYKDWWNSTSYANYYRTWNVVVHDWLYYYVYRDFLWMTOKRFRAVAMLVVFTVSAVVHE 458 Hs_DGAT1 319 IIERLLKLAVPNHLIWLIFFYWLFHSCLNAVAELMQFGDREFYRDWWNSESVTYFWQNWNIPVHKWCIRHFYKPMLRRGSSKW--MARTGVFLASAFFHE 416

M8

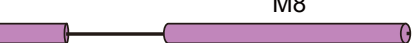

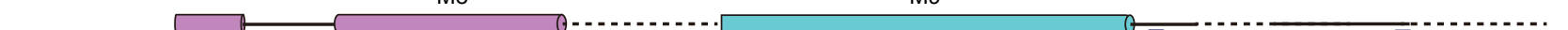

HS_SOAT1 462 YALAVCLSFFYPVLFVLFMFFGMA----FNFIVNDSRKKP IWNVLMWTSLFLGNGVLLCFYSQEWYARQH-CPLKNPTFLDYVRPRSWTC--RYVF----- 550 Hs_SOAT2 436 YIFCFVLGFFYPVMLILFLVIGGM----LNFMMHDQRTGPAWNVLMWTMLFLGQGIQVSLYCQEWYARRH-CPLPQATFWGLVTPRSWSC--HT------- 522 Gg_SOAT1 472 YVLSICFGFFYPVLFCLFMCFGML----FNFILNDRRKGP IWNVIMWTSLFLGOGVIICLYSOEWYAROY-CPAENPAFLDYLKPRSWSC--HVOM---- 560 X1_SOAT1 460 YAT X1_SOAT1 460 YALGICEGEYPVLFILMCEGML_Dr_SOAT1 459 YVLAICFGFFYPVMFCLFMCFGMV----FNFVLHDRRKGP IWNVIMWTSLFLGQGVMICLYSQEWYAQRY-CPIEEPSLIDLLKPRSWTCYPQTNAAFDS 553 HS_DGAT1 417 YLVSVPLR-----MFRLWAFTGMMAQIPLAWFVGRFFQGNYGNAAVWLSLIIGQPIAVLMYVHDYYVLNYEAPAAEA------------ ----------- 488

Fig. S7 | Sequence alignments of HsSOAT1, HsSOAT2, GgSOAT1, XISOAT1, DrSOAT1 and HsDGAT1. The secondary structure elements are shown above the sequences $(\alpha-$ helices as cylinders, loops as lines and unmodeled residues as dashed lines). Conserved and highly conserved residues are highlighted in gray. Cylinders are colored in rainbow colors according to Fig. 3d. The active site H460 is boxed in red. Two cysteines forming the disulfide bond in the ER lumen are boxed in blue. Residues that interact with the putative sterol-like molecule are boxed in green. Hs: homo sapiens, Gg: Gallus gallus, Xl: Xenopus laevis, Dr: Danio rerio. 
bioRxiv preprint doi: https://doi.org/10.1101/2020.01.07.897124; this version posted January 8, 2020. The copyright holder for this preprint (which was not certified by peer review) is the author/funder, who has granted bioRxiv a license to display the preprint in perpetuity. It is made Cl-grkailable under aCC-BY-NC-ND 4.0 InternationaApie étase.e.
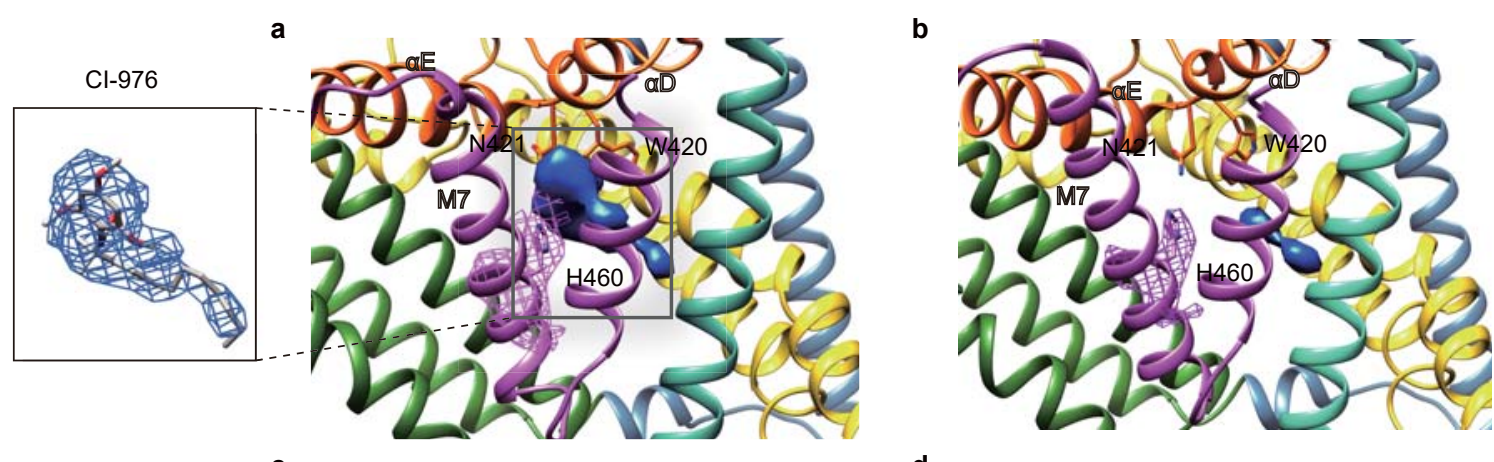

C

d
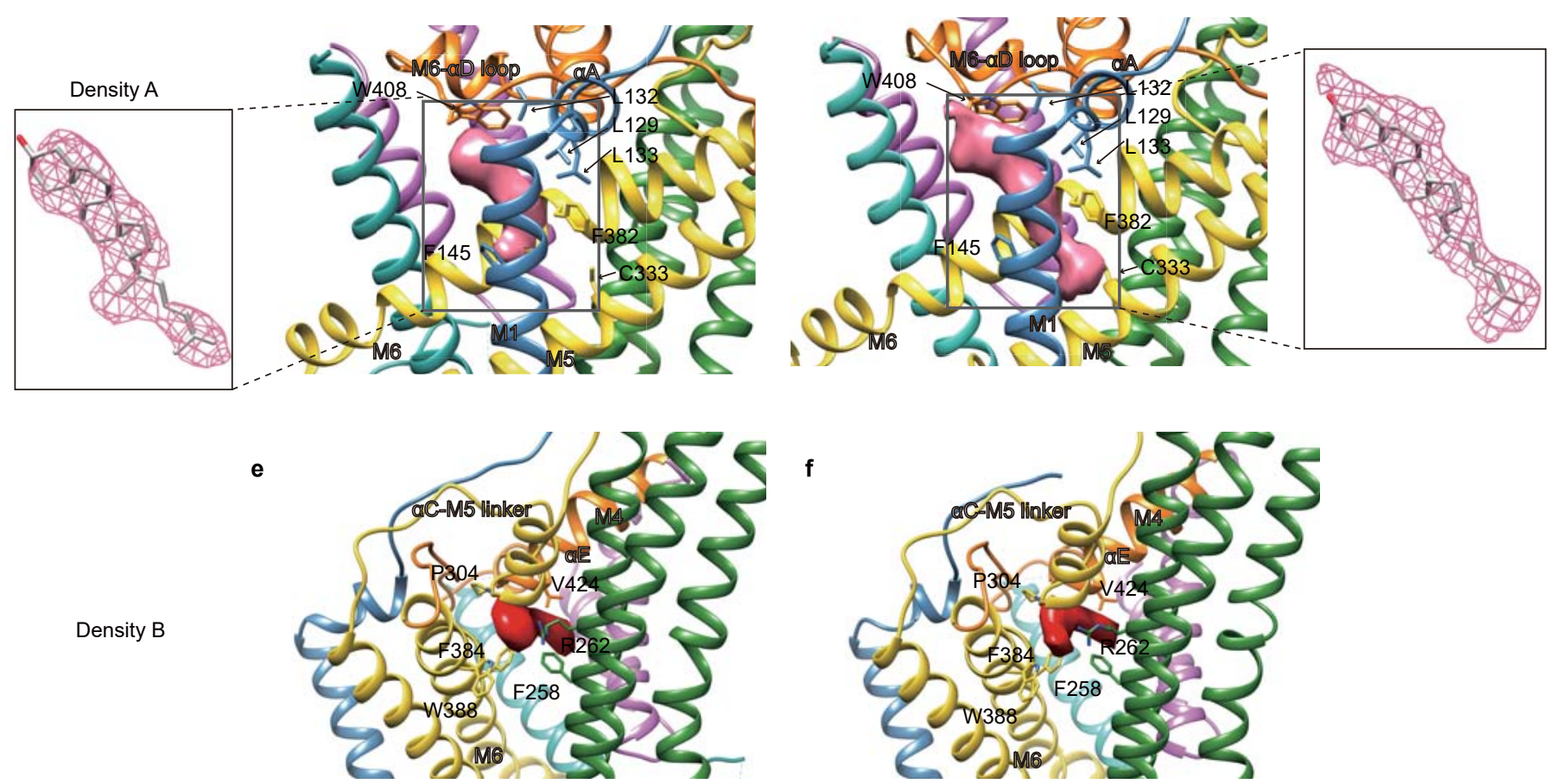

g
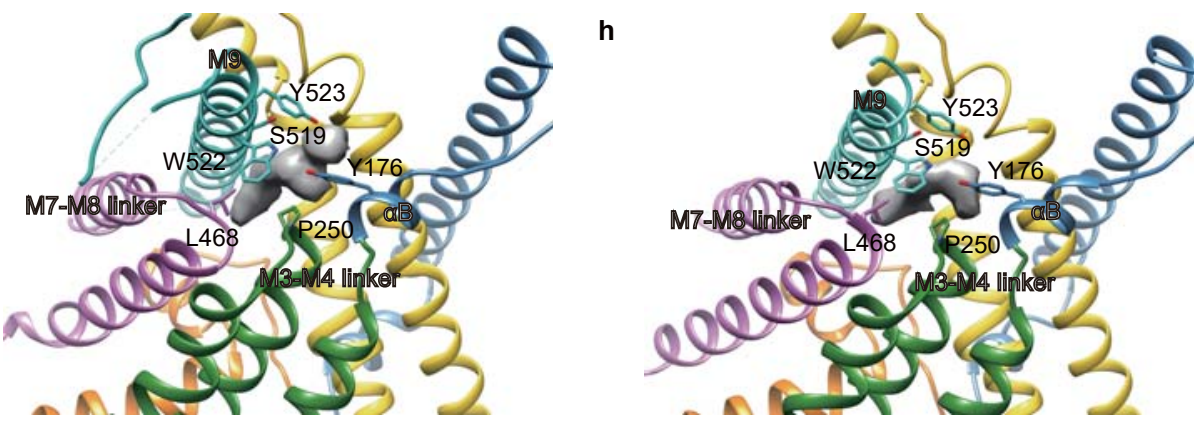

Fig. S8 | Electron density maps of bound ligands. a-b, Local EM densities inside the catalytic chamber in hSOAT1 dimer maps in complex with CI-976 (a) and in apo state (b). The inhibitor CI-976 density in (a) is shown as blue surface. The weak residual density in the BiSAS map is also shown as blue surface. The density of H460 side chains is shown in pink meshes at the same contour level as the ligand density in blue. c-d, The sterol-like densities (density A) in the maps of hSOAT1 dimer in complex with CI-976 (c) and in apo state (d) are shown in pink. The close-up view of the density with a sterol-like molecule inside is shown in boxes. e-f, The putative ligand densities (density B) in the maps of hSOAT1 dimer in complex with CI-976 (e) and in apo state (f) are shown in red. g-h, The putative ligand densities (density C) in the maps of hSOAT1 dimer in complex with CI-976 (g) and in apo state (h) are shown in grey. 
bioRxiv preprint doi: https://doi.org/10.1101/2020.01.07.897124; this version posted January 8, 2020. The copyright holder for this preprint (which was not certified by peer review) is the author/funder, who has granted bioRxiv a license to display the preprint in perpetuity. It is made available under aCC-BY-NC-ND 4.0 International license.

a

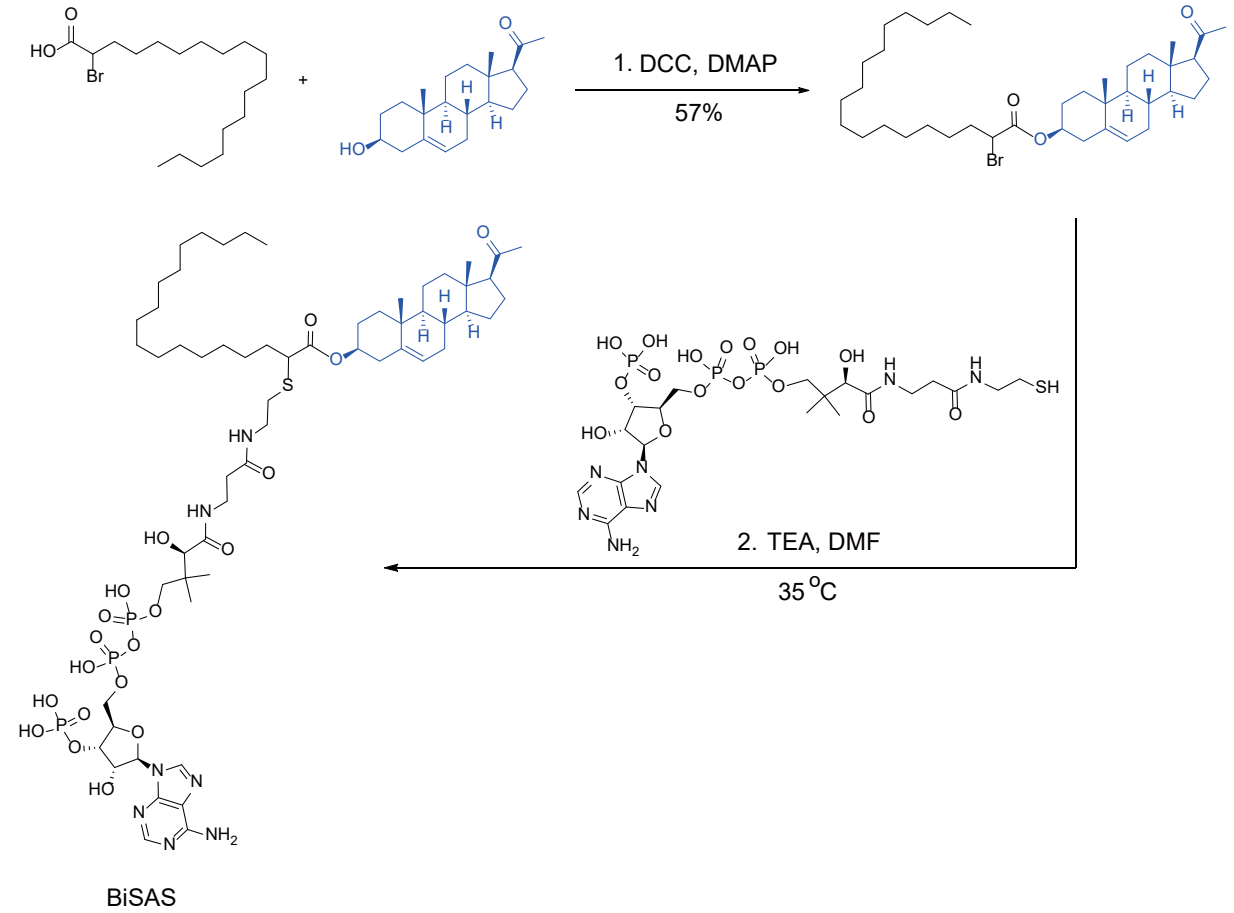

b

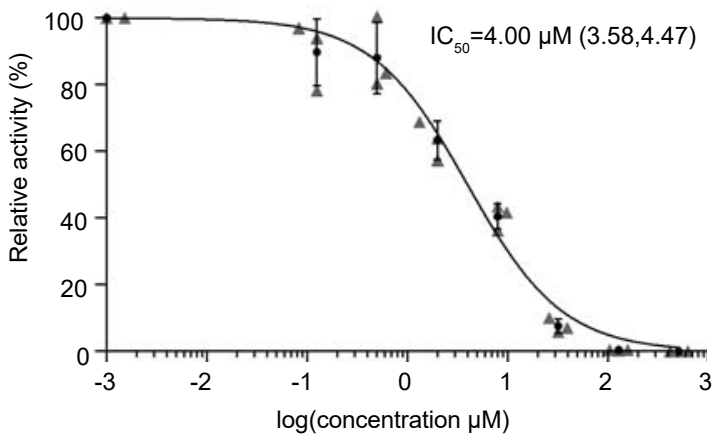

Fig. S9 | The chemical synthesis of BiSAS. a, Design and synthesis of BiSAS. b, Dose-dependent inhibition curve of hSOAT1 tetramer by BiSAS (The first data point is an artificial point. Data are shown as means \pm standard deviations, $\mathrm{n}=3$ biologically independent samples). 
bioRxiv preprint doi: https://doi.org/10.1101/2020.01.07.897124; this version posted January 8, 2020. The copyright holder for this preprint (which was not certified by peer review) is the author/funder, who has granted bioRxiv a license to display the preprint in perpetuity. It is made

a

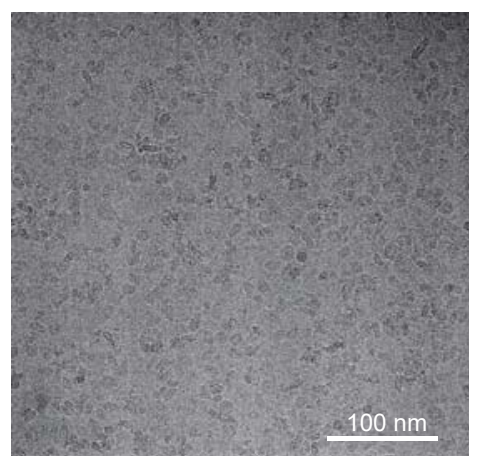

BD 4.0 International license.

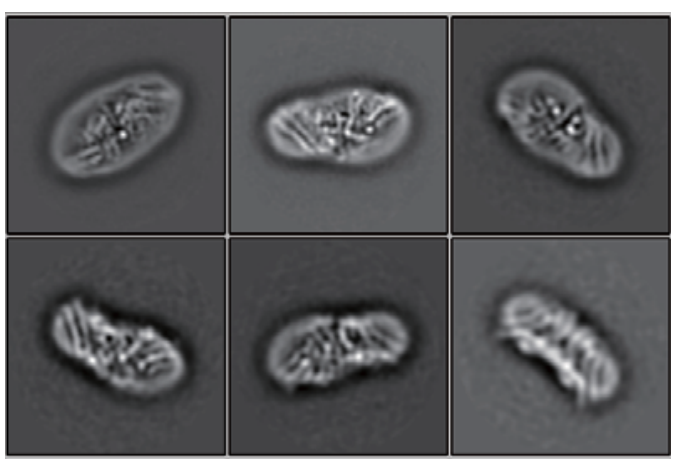

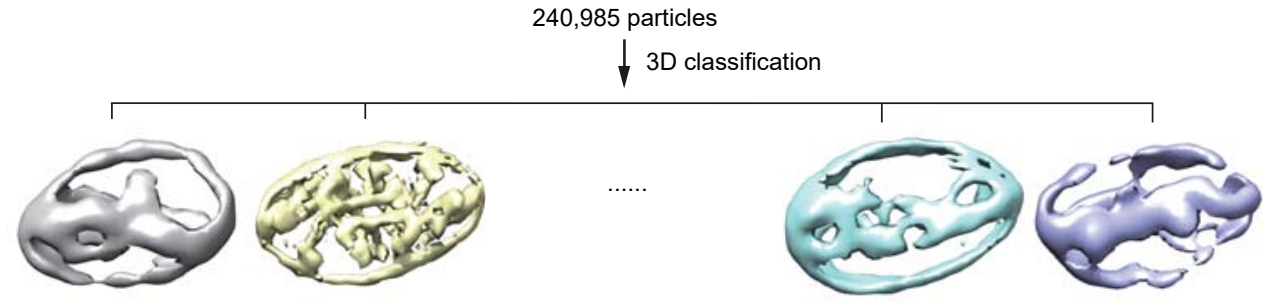

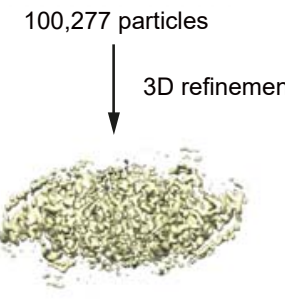

$3.5 \AA$

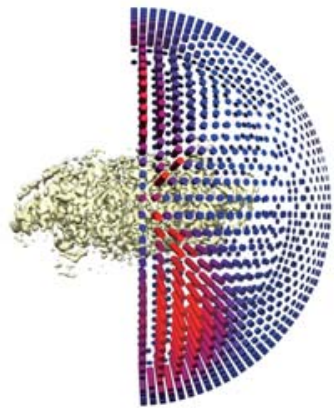

d

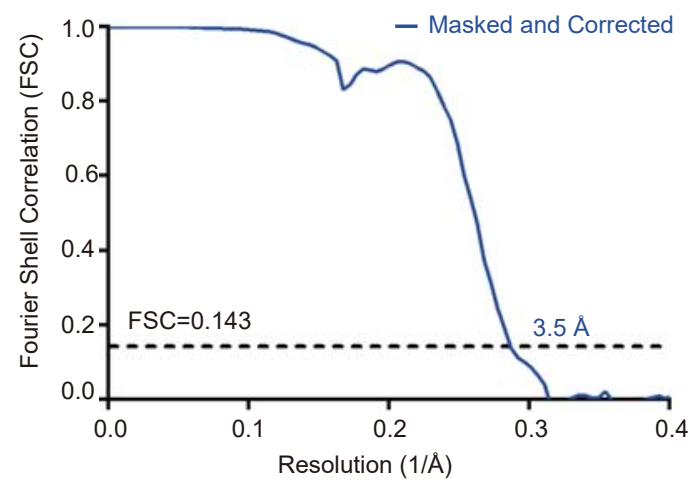

Fig. S10 | Cryo-EM image processing procedure of the hSOAT1 dimer in apo state. a, Representative raw micrograph of hSOAT1 dimer in apo state. b, Representative 2D class averages of the cryo-EM particles of hSOAT1 dimer in apo state. c, Flowchart of the image processing procedure for hSOAT1 dimer in apo state. d, Gold-standard Fourier shell correlation (FSC) curve of the final refined map for hSOAT1 dimer in apo state. Resolution estimation (3.5 $\AA$ ) is based on the criterion of the gold-standard FSC cutoff at 0.143 in Relion. 
bioRxiv preprint doi: https://doi.org/10.1101/2020.01.07.897124; this version posted January 8, 2020. The copyright holder for this preprint (which was not certified by peer review) is the author/funder, who has granted bioRxiv a license to display the preprint in perpetuity. It is made available under aCC-BY-NC-ND 4.0 International license.

a

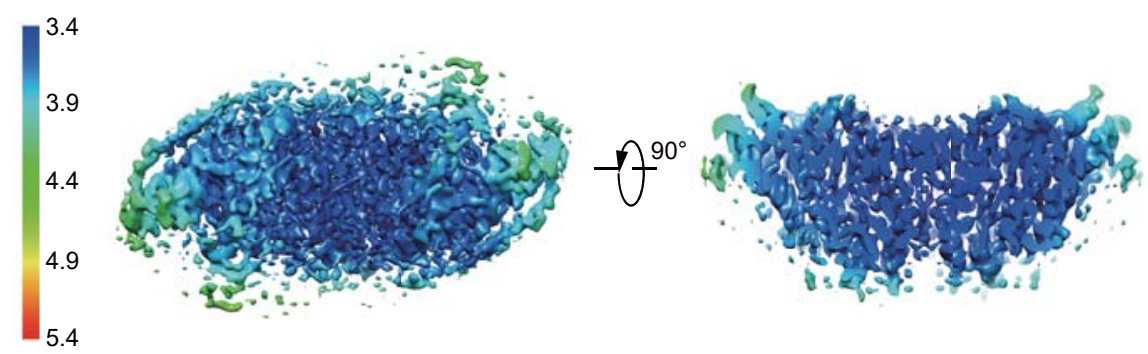

b

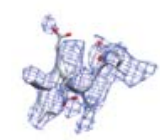

$\alpha \mathrm{A}$

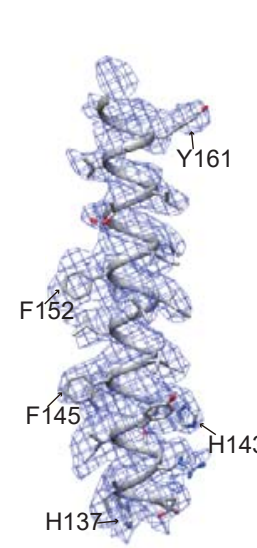

M1

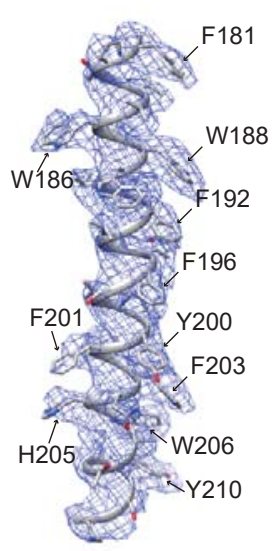

M2

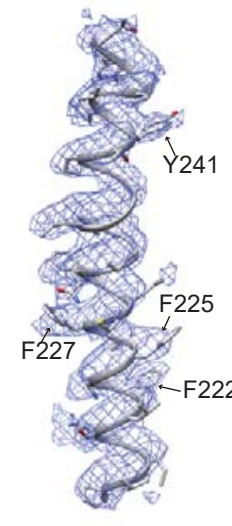

M3

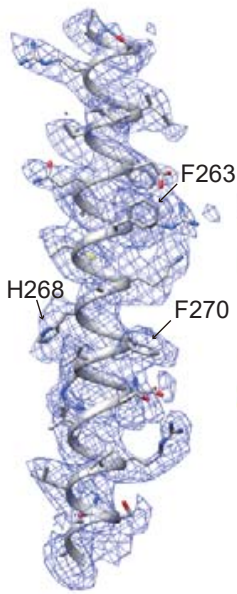

M4

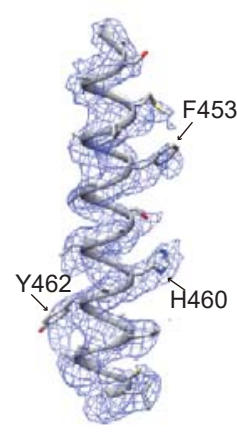

M7

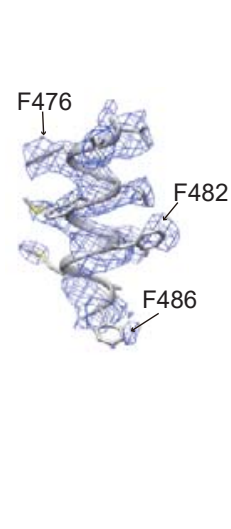

M8

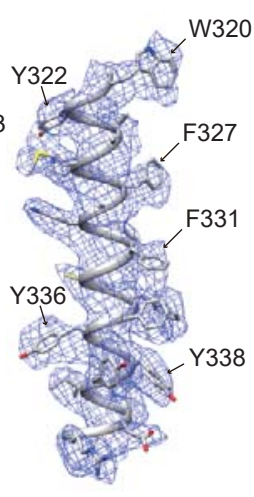

M5

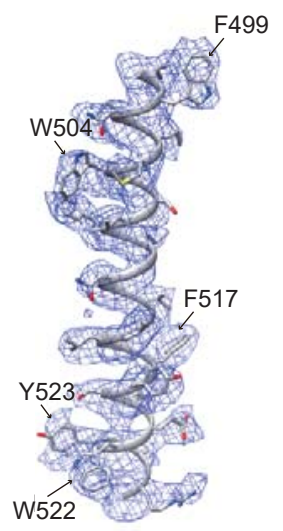

M9

Fig. S11 | Electron density map of the hSOAT1 dimer in apo state. a Top view and cut-away representations of the hSOAT1 dimer cryo-EM density map in apo state colored according to the local resolution estimation. b, EM density segments (blue mesh) of the 9 transmembrane helices (M1-M9), $\alpha \mathrm{A}$ and $\alpha \mathrm{D}-\alpha \mathrm{E}$, . 
bioRxiv preprint doi: https://doi.org/10.1101/2020.01.07.897124; this version posted January 8, 2020. The copyright holder for this preprint (which was not certified by peer review) is the author/funder, who has granted bioRxiv a license to display the preprint in perpetuity. It is made available under aCC-BY-NC-ND 4.0 International license.

a

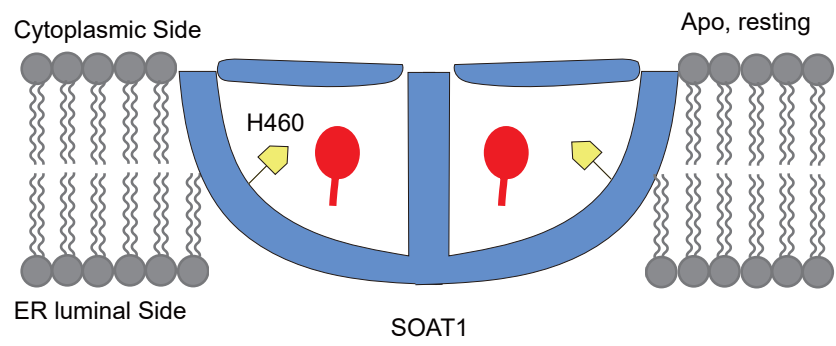

b

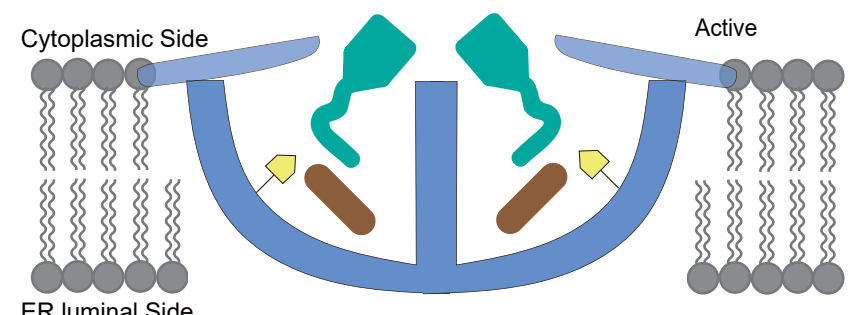

SOAT1
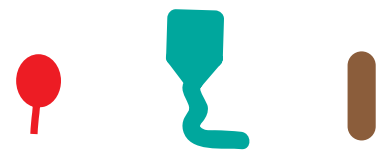

Cl-976

Oleoyl-CoA Cholesterol

Fig. S12 | A working model to explain hSOAT1 activation. In the resting state, the putative catalytic residue H460 colored in yellow is less accessible to the acylCoA substrate. In the activation step, the lid of the reaction chamber is open; this step is required to activate the esterification reaction between acyl-CoA and cholesterol. For simplicity, only one SOAT1 dimer is shown. 